\title{
Corporate Governance, Product Market Competition, and Equity Prices*
}

\author{
Xavier Giroud $^{\dagger} \quad$ Holger M. Mueller ${ }^{\ddagger}$
}

August 2008

\begin{abstract}
This paper examines the hypothesis that firms in competitive industries should benefit relatively less from good governance, while firms in non-competitive industries - where lack of competitive pressure fails to enforce discipline on managers - should benefit relatively more. Whether we look at the effects of governance on long-horizon stock returns, firm value, or operating performance, we consistently find the same pattern: The effect is monotonic in the degree of competition, it is small and insignificant in competitive industries, and it is large and significant in non-competitive industries. By implication, the effect of governance (in non-competitive industries) reported in this paper is stronger than what has been previously reported in Gompers, Ishii, and Metrick (2003, "GIM") and subsequent work, who document the average effect across all industries. For instance, GIM's hedge portfolio-provided it only includes firms in non-competitive industries - earns a monthly alpha of $1.47 \%$, which is twice as large as the alpha reported in GIM. The alpha remains large and significant even if the sample period is extended until 2006. We also revisit the argument that investors in the 1990s anticipated the effect of governance, implying that the alpha earned by GIM's hedge portfolio is likely due to an omitted risk factor. We find that while investors were indeed not surprised on average, they underestimated the effect of governance in non-competitive industries, the very industries in which governance has a significant effect in the first place.
\end{abstract}

\footnotetext{
*We thank seminar participants at MIT, Kellogg, NYU, the workshop "Understanding Corporate Governance" in Madrid (2008), and the NBER Corporate Finance Summer Institute in Cambridge (2008), where part of this research has been presented.

${ }^{\dagger}$ New York University. Email: xgiroud@stern.nyu.edu.

${ }^{\ddagger}$ New York University, CEPR, \& ECGI. Email: hmueller@stern.nyu.edu.
} 


\section{Introduction}

Do all firms benefit from good corporate governance? While this question may sound like blasphemy in the ears of shareholder-rights activists, it is not without substance. Going back to Adam Smith, economists have long argued that managerial incentive problems are first and foremost an issue for firms in non-competitive industries. As Sir John Hicks succinctly put it, managers of such firms tend to enjoy the "quiet life". ${ }^{1}$ By contrast, managers of firms in competitive industries are under constant pressure to reduce slack and improve efficiency, or else they will not survive. Hence, survival of the fittest, the quintessential Darwinian concept, ensures that managers in competitive industries have little choice but to maximize firm value: ${ }^{2}$

"Over the long pull, there is one simple criterion for the survival of a business enterprise: Profits must be nonnegative. No matter how strongly managers prefer to pursue other objectives [...] failure to satisfy this criterion means ultimately that a firm will disappear from the economic scene." (Scherer, 1980)

That firms benefit from good corporate governance on average is well established. In an influential paper, Gompers, Ishii, and Metrick (2003, henceforth "GIM") demonstrate that firms with good governance earn significantly higher stock returns. The authors construct a hedge portfolio that is long in firms with good governance ("Democracy firms") and short in firms with bad governance ("Dictatorship firms"). Over a 10-year horizon (1990 to 1999), this hedge portfolio earns a monthly alpha of $0.67 \%$, which corresponds to an annual alpha of about $8.5 \%$. Governance is measured via an index ("G-index") consisting of 24 (anti-)governance provisions. In addition to showing that good governance is associated with higher stock returns, GIM also show that it is positively related to firm value and operating performance. ${ }^{3}$

\footnotetext{
1 "The best of all monopoly profits is a quiet life" (Hicks (1935)). Similarly, Adam Smith (1776) writes that "Monopoly [...] is a great enemy to good management".

${ }^{2}$ This (extreme) version of the notion that product market competition reduces managerial slack, based on survivorship, is due to Alchian (1950), Friedman (1953), and Stigler (1958). A formal model along these lines has been developed by Winter (1971).

${ }^{3}$ The latter evidence is not causal, though the authors do examine alternative hypotheses and find no evidence that their results are driven by either reverse causality or an omitted variable bias. However, other papers have shown that governance - proxied for by the passage of state takover laws - has a causal effect on firms' operating performance (Bertrand and Mullainathan (2003); Giroud and Mueller (2008)).
} 
If managers of firms in competitive industries have little choice but to maximize firm value, then firms in such industries should benefit relatively less from good governance. In contrast, firms in non-competitive industries, where lack of competitive pressure fails to enforce discipline on managers, should benefit relatively more. The evidence presented in this paper supports this hypothesis. Whether we look at the effects of governance on stock returns, firm value, or operating performance, we consistently find that the effect is small and insignificant in competitive industries, while it is large and significant in non-competitive industries. ${ }^{4}$ By construction, since the results in GIM and subsequent work document the average effect across all industries, this implies that the effects of governance (in non-competitive industries) reported in this paper are stronger than what has been previously documented. On a practical note, our results imply that researchers who want to investigate the effects of governance could benefit from interacting governance with measures of competition. In fact, researchers might find that governance has a strong and significant effect in non-competitive industries even if the average effect across all industries is small and insignificant (see below for examples).

Our main measure of competition is the Herfindahl-Hirschman index ("HHI"). The index is computed for each of the 48 Fama-French (1997) industries based on all firms in the Compustat universe. We construct hedge portfolios by dividing both the Democracy (G-index of 5 or less) and Dictatorship (G-index of 14 or higher) portfolios each into equal-sized portfolios based on whether the HHI lies in the lowest, medium, or highest tercile of its empirical distribution. For each HHI tercile, we then form a hedge portfolio that is long in the respective Democracy portfolio and short in the respective Dictatorship portfolio. For the original sample period in GIM (1990 to 1999), we find that the alpha earned by the hedge portfolio is small and insignificant in the lowest HHI tercile (competitive industries), it is larger and marginally significant in the medium HHI tercile, and it is largest and significant in the highest HHI tercile (non-competitive industries). For instance, the alpha in the highest HHI tercile is $1.47 \%$ per month, which is approximately twice as large as the alpha reported in GIM.

This pattern is robust across many specifications. Whether we use different competition measures (e.g., measures provided by the Census Bureau, which include all public and private

\footnotetext{
${ }^{4}$ Using the passage of state takeover laws as a source of exogenous variation, Giroud and Mueller (2008) find that these laws have no effect on firms' operating performance in competitive industries, while they have a strong effect on firms in non-competitive industries. Their paper does not consider firm-level governance mechanisms, however, nor does it consider the effect of governance on either long-horizon stock returns or firm value.
} 
firms), different governance measures (e.g., the E-index by Bebchuk, Cohen, and Ferrell (2005) or the ATI by Cremers and Nair (2005)), or whether we extend the sample period until 2006, the alpha is always monotonic in the HHI, it is always small and insignificant in the lowest HHI tercile, and it is always large and significant in the highest HHI tercile. The latter robustness check - extending the sample period until 2006 - is particularly interesting, as it has been shown that the original results of GIM all but disappear when the sample period is extended beyond 1999. When we extend the sample period until 2006, we do indeed find that the alpha is small and insignificant on average. However, the alpha remains large (0.99\%) and significant in the highest HHI tercile. Overall, our results strenghten GIM's findings that governancebased trading strategies earn significant abnormal returns, especially if they focus on firms in non-competitive industries.

A valid question is whether the significant abnormal returns in the highest HHI tercile are driven by industry effects and not by corporate governance. We examine this possibility using both industry-adjusted returns and a five-factor model that includes the HHI as an additional risk factor. The results remain virtually unchanged. Another issue, and one that is already present in GIM's original study, is whether the results could be driven by an omitted variable bias. Such a bias could arise if governance provisions are correlated with firm or other (risk) characteristics that were priced during the sample period but that are not captured by the asset pricing model used to calculate abnormal returns. To address this issue, we follow GIM and estimate Fama-MacBeth return regressions that include a broad array of control variables. The picture is similar to before. The effect of governance on stock returns is monotonic in the HHI, it is small and insignificant in the lowest HHI tercile, and it is large and significant in the highest HHI tercile.

There are two potential explanations for the abnormal returns earned by the DemocracyDictatorship hedge portfolio. ${ }^{5}$ One is an omitted variable bias. As we have stated above, and consistent with GIM's own findings, we find no evidence for this hypothesis. The other explanation is that weak governance gives rise to agency costs whose magnitude was underestimated by investors. Consistent with the first part of this hypothesis, GIM find that weak governance is associated with both higher capital expenditures and higher acquisition activity, while Core,

\footnotetext{
${ }^{5}$ GIM also propose a third explanation, which is based on reverse causality: Managers who rationally anticipate the poor future performance of their companies adopt takeover defenses and weaken shareholder rights to shield their jobs from shareholder activism and hostile takeovers. GIM find no evidence for this hypothesis.
} 
Guay, and Rusticus (2006) and GIM both find that weak governance is associated with lower operating performance. However, Core, Guay, and Rusticus find no evidence for the second part of the hypothesis, namely, that investors were surprised. The authors test whether the stock market underperformance of weak governance firms is due to investor surprise about the poor operating performance of these firms. Using analysts' earnings forecasts to proxy for investors' expectations, they find no significant relation between governance and forecast errors (difference between actual and forecasted earnings per share (EPS)).

Consistent with Core, Guay, and Rusticus' results, we (also) find that the average forecast error is small and insignificant. However, when we-based on our previous findings - examine how this result varies across HHI terciles, we obtain a more nuanced picture. First, we find that good governance firms exhibit significantly higher EPS only when competition is weak. Second, and this is remarkable, analysts seem to understand that good governance has a positive effect only in non-competitive industries. While the difference in forecasted EPS between good and bad governance firms is small and insignificant in the lowest and medium HHI terciles, it is large and significant in the highest HHI tercile. However, and herein lies the crux, analysts seem to underestimate the magnitude of the effect of good governance on EPS in non-competitive industries. While the forecast error is small and insignificant in the lowest and medium HHI terciles, it is positive and significant in the highest HHI tercile. Thus, analysts underestimate the effect of good governance on EPS in precisely those industries in which governance matters for EPS. Whether this forecast error is large enough to fully explain the abnormal returns is an open question. At a minimum, it provides evidence in support of the hypothesis that investors were surprised, which is consistent with GIM's interpretation of their findings.

We next consider the effect of governance on firm value (Tobin's Q). We estimate crosssectional regressions of industry-adjusted Q on the G-index (or the G-index interacted with HHI dummies) and controls for each year from 1990 to 2006. Consistent with GIM's results, we find that governance has a significant positive effect on firm value in 14 out of 17 years. Interestingly, the estimates after 1999 are similar to those before, suggesting that the relation between governance and firm value does not weaken after 1999. When we examine how this result varies across HHI terciles, we obtain the same pattern as before. The effect of governance on firm value is monotonic in the HHI in most years (13 out of 17 years), it is always small and insignificant in the lowest HHI tercile, and it is always positive, economically large, and almost 
always significant (16 out of 17 years) in the highest HHI tercile. We obtain the same picture for the overall sample period (1990 to 2006) when using either the Fama-MacBeth methodology or a panel regression with fixed effects and clustered standard errors.

We finally consider the effect of governance on firms' operating performance, measured by the return on assets (ROA), net profit margin (NPM), and return on equity (ROE). In all three cases, we find that governance has on average a positive effect on operating performance, although the effect is only significant for ROA and NPM. ${ }^{6}$ When we examine how these results vary across HHI terciles, we obtain the same picture as before. The effect of governance on operating performance is always monotonic in the HHI, it is always small and insignificant in the lowest HHI tercile, and it is always large and significant in the highest HHI tercile. This is true even for ROE, where the average effect is insignificant. Overall, our results regarding firm value and operating performance are consistent with those obtained in the context of equity returns. While governance appears to matter only little in competitive industries, it has a positive and significant effect in non-competitive industries.

The rest of this paper is organized as follows. Section 2 describes the data and provides summary statistics on the empirical relation between the G-index and the HHI. Section 3 examines the effect of governance on equity returns. Section 4 examines the effect on firm value and operating performance. Section 5 concludes.

\section{Data}

\subsection{Sample Selection and Definition of Variables}

Our sample consists of all companies in the Investor Responsibility Research Center (IRRC) universe that have a match in both CRSP and Compustat. We exclude all firms with dual-class shares. ${ }^{7}$ To match firms to industries, we require a non-missing SIC code in Compustat. Over the sample period from 1990 to 2006, this leaves us with 3,241 companies.

Our measure of corporate governance is the Governance Index ("G-index") developed by GIM. The index is constructed by adding one index point for each of the 24 (anti-)corporate governance provisions listed in GIM. Higher index values indicate weaker corporate governance.

\footnotetext{
${ }^{6}$ That the (average) effect of governance on ROE is insignificant is consistent with GIM's results.

${ }^{7}$ See GIM, footnote 5 .
} 
GIM refer to companies with a G-index of 5 or less as "Democracies" and to companies with a G-index of 14 or higher as "Dictatorships". The G-index is obtained from the IRRC database and is available for the years 1990, 1993, 1995, 1998, 2000, 2002, 2004, and 2006 during the sample period. For intermediate years, we use the index value from the latest available year. In robustness checks, we will also use the Entrenchment Index ("E-index") by Bebchuk, Cohen, and Ferrell (2005) and the Alternative Takeover Index ("ATI") by Cremers and Nair (2005). The E-index consists of 6 out of the 24 provisions listed in GIM. The ATI is based on only 3 provisions. ${ }^{8}$ We construct the E-index and the ATI using IRRC data. The correlations between all three indices are high. Using all IRRC years, the correlation between the G-index and the E-index is 0.71, the correlation between the G-index and the ATI is 0.68 , and the correlation between the E-index and the ATI is 0.76 .

Our measure of product market competition is the Herfindahl-Hirschman index ("HHI"). The index is computed as the sum of squared market shares,

$$
H H I_{j t}:=\sum_{i=1}^{N_{j}} s_{i j t}^{2}
$$

where $s_{i j t}$ is the market share of firm $i$ in industry $j$ in year $t$. Market shares are computed from Compustat using firms' sales (item \#12). When computing the HHI, we use all firms in the Compustat universe. We exclude firm-year observations for which sales are either missing or negative. The HHI is a commonly used measure in the empirical IO literature and is well grounded in theory (Curry and George (1983); Tirole (1988, pp. 221-223)). In robustness checks, we will also use the four-firm concentration ratio, which is the sum of market shares of the four largest firms in an industry. This measure is also common in the empirical IO literature and is routinely used by government agencies.

We classify industries using the 48 industry classification scheme by Fama and French (1997, henceforth FF). We assign each company to an industry by matching the SIC codes of Compustat to the $48 \mathrm{FF}$ industries using the conversion table in the Appendix of FF. We obtain similar results if we use alternative industry partitions, such as the Standard Industry Classification (SIC), the North-American Industry Classification System (NAICS), and the Global Industry

\footnotetext{
${ }^{8}$ For the E-index, we use a cutoff of $\mathrm{E}=0$ for Democracy firms and $\mathrm{E} \geq 4$ for Dictatorship firms. Using a cutoff of $E \geq 4$ ensures that the Dictatorship portfolio contains sufficiently many companies relative to the Democracy portfolio (see Table II in Bebchuk, Cohen, and Ferrell (2005)). For the ATI, we use a cutoff of ATI $=0$ for Democracy firms and ATI $\geq 2$ for Dictatorship firms.
} 
Classification Standard (GICS). ${ }^{9}$

Since our competition measures are computed from Compustat, they only include publicly traded companies. In robustness checks, we will alternatively use competition measures provided by the Census Bureau (HHI and four-firm concentration ratio, respectively), which include all public and private firms in the U.S. Despite this appealing feature, the measures provided by the Census Bureau have some serious drawbacks. First, they are only available for manufacturing industries. ${ }^{10}$ Second, they are only computed every five years. Since our sample ranges from 1990 to 2006, we use data from the 1987, 1992, 1997, and 2002 Censuses. For intermediate years, we use the data from the latest available Census. Third, the measures are not available for the $48 \mathrm{FF}$ industries. In the 1987 and 1992 Censuses, they are only available for 4-digit SIC industries. In 1997, the Census Bureau switched from SIC to NAICS codes and began to provide competition measures for various NAICS partitions. In our empirical analysis, we use 4-digit SIC codes before 1997 and 4-digit NAICS codes after 1997. We obtain similar results if we use 5- or 6-digit NAICS codes after 1997.

We will also use data from CRSP, CDA Spectrum, I/B/E/S, and other sources. The respective variables are all standard in the finance literature and will be introduced later.

\subsection{Empirical Relation between the G-index and the HHI}

Using all firm-year observations from 1990 to 2006, the correlation between the G-index and the HHI is virtually zero. ${ }^{11}$ (The correlation is 0.00 with a $p$-value of 0.50 .) Since the HHI is an industry measure, we can also compute the correlation at the industry level. Here, we obtain a weakly negative correlation of -0.06 ( $p$-value of 0.08 ) between the HHI and the mean G-index of an industry. ${ }^{12}$ Since our analysis is entirely at the firm level, however, the relevant correlation from our perspective is at the firm level.

\footnotetext{
${ }^{9}$ The NAICS and GICS codes can be obtained from the Prices, Dividends, and Earnings file of Compustat.

${ }^{10}$ From 1997 onward, the four-firm concentration ratio is available for all NAICS industries, except mining, construction, and management of companies and enterprises. To avoid that our results are driven by changes in industry composition, we use this measure only for manufacturing industries. However, we have verified that our results are similar if we use all available industries.

${ }^{11}$ This has been already noted by GIM (p. 119), who write that "[t]here is no obvious industry concentration among these top firms [in the Democracy and Dictatorship portfolios]."

${ }^{12}$ This is consistent with findings by Cremers, Nair, and Peyer (2008).
} 
Table I provides detailed statistics. Panel (A) includes all firms in the Democracy and Dictatorship portfolios. For each of these two portfolios, we sort firms into quintiles based on their HHIs. The comparison of interest is between firms in the Democracy and Dictatorship portfolios that lie in the same HHI quintile. As is shown, the distribution of the HHI in the Democracy and Dictatorship portfolios is virtually identical. For example, firms in the lowest HHI quintile of the Democracy portfolio have a mean (median) HHI of 0.02 (0.02), as do firms in the lowest HHI quintile of the Dictatorship portfolio. Likewise, the range of observed HHI values in the lowest quintile is $[0.01,0.03]$ in either of the two portfolios. The picture is similar in the other four quintiles.

Panel (B) includes all firms, not just those in the Democracy and Dictatorship portfolios, and sorts them into HHI quintiles. As is shown, the mean G-index is similar and the median G-index is identical in all five quintiles. Importantly, there is no systematic trend. Starting from the lowest quintile, the mean G-index first decreases, then it increases twice, and then it decreases. The mean G-index in the highest HHI quintile is 9.19, which is close to the value in the lowest quintile (9.22). The range of observed G-index values is also similar across HHI quintiles. Effectively, this means that it does not matter whether we sort firms first by their G-index and then by their HHIs, or the other way around.

We obtain similar bivariate statistics if we use either the E-index or the ATI instead of the G-index, if we use the HHI provided by the Census Bureau instead of the HHI computed from Compustat, and if we restrict the sample to the original period in GIM (1990 to 1999) or the post-GIM period (2000 to 2006).

\section{Return Regressions}

\subsection{Trading Strategies}

This section examines the performance of trading strategies that are jointly based on corporate governance and product market competition. To compute abnormal returns, we use Carhart's (1997) four-factor model. The abnormal return is the intercept $\alpha$ of the regression

$$
R_{t}=\alpha+\beta_{1} \times R M R F_{t}+\beta_{2} \times S M B_{t}+\beta_{3} \times H M L_{t}+\beta_{4} \times U M D_{t}+\varepsilon_{t},
$$

where $R_{t}$ is the excess return on a given portfolio in month $t, R M R F_{t}$ is the return on the market portfolio minus the risk-free rate, $S M B_{t}$ is the size factor (small minus big), $H M L_{t}$ 
is the book-to-market factor (high minus low), and $U M D_{t}$ is the momentum factor (up minus down). To construct portfolio returns, we use monthly returns from CRSP. The $R M R F, S M B$ and $H M L$ factors are taken from Kenneth French's website, while $U M D$ is computed using the procedure described in Carhart (1997).

GIM construct a hedge portfolio that is long in the Democracy portfolio (firms with a Gindex of 5 or less) and short in the Dictatorship portfolio (firms with a G-index of 14 or higher). To analyze the joint effect of governance and competition, we divide both the Democracy and Dictatorship portfolio each into equal-sized portfolios based on HHI terciles. This leaves us with $2 \times 3=6$ portfolios: one Democracy portfolio and one Dictatorship portfolio for each HHI tercile. $^{13}$ For each HHI tercile, we then construct a hedge portfolio analogous to GIM that is long in the respective Democracy portfolio and short in the respective Dictatorship portfolio. In our benchmark analysis, we also construct hedge portfolios based on two (instead of three) HHI groups. ${ }^{14}$

To allow a comparison with GIM's results, we use the same sample period, namely, from September 1990 to December 1999 (112 monthly returns). In robustness checks, we will extend the sample period until December 2006. Analogous to GIM, we rebalance all portfolios in September 1990, July 1993, July 1995, and February 1998, which are the months after which new IRRC data became available. To incorporate new values of the HHI, we additionally rebalance all portfolios each July using the HHI computed from sales in the previous fiscal year. ${ }^{15}$ We always report the results both for value-weighted and equally-weighted portfolios. To compute the value-weighted return on a portfolio in month $t$, we weight each individual return with the stock's market capitalization at the end of month $t-1$.

\section{Main Results}

Table II contains our main results. In the first row of Panel (A), we report the original results by GIM. For value-weighted portfolios, GIM find that the Democracy-Dictatorship hedge

\footnotetext{
${ }^{13}$ Our results are virtually unchanged if we sort firms first by their HHIs and then according to whether they are Democracy or Dictatorship firms. This is not surprising given that the correlation between the HHI and the G-index on the firm level is virtually zero.

${ }^{14}$ We obtain similar results if we form hedge portfolios based on HHI quartiles. We use HHI terciles as our preferred partition to ensure that each portfolio contains sufficiently many companies.

${ }^{15}$ We obtain similar results if we use the HHI from the fiscal year $t-2$ or a moving average of the HHIs over the previous three fiscal years.
} 
portfolio earns a monthly alpha of $0.71 \%(t=2.73)$. In the second row, we replicate GIM's results. The alpha $(0.69 \%, t=2.71)$ and factor loadings are similar, albeit not identical. ${ }^{16}$ In the third row, we exclude all companies with missing SIC codes. ${ }^{17}$ This is the sample we will use in our analysis. The alpha $(0.66 \%, t=2.57)$ and factor loadings are again similar, which suggests that the excluded companies are not different from the rest.

In Panel (B), we report the abnormal returns to the Democracy-Dictatorship hedge portfolios based on individual HHI groups. All portfolios are value-weighted. If we form hedge portfolios based on two HHI groups, we find that the alpha is small (0.43\%) and insignificant in the belowmedian HHI group (competitive industries), while it is large $(1.08 \%)$ and significant $(t=3.13)$ in the above-median HHI group. A similar picture emerges if we form hedge portfolios based on three HHI groups. The alpha is small $(0.30 \%)$ and insignificant in the lowest HHI tercile, it is larger $(0.64 \%)$ and marginally significant $(t=1.70)$ in the medium HHI tercile, and it is largest $(1.47 \%)$ and significant $(t=3.38)$ in the highest HHI tercile. ${ }^{18}$

There are two ways how to interpret our results. One interpretation is that governancebased trading strategies are ineffective in competitive industries. The other interpretation, which is merely the other side of the coin, is that governance-based trading strategies are highly effective in non-competitive industries. In fact, since the alphas in GIM are averages across all industries, our results show that governance-based trading strategies, provided they focus on non-competitive industries, are more effective than previously documented. For instance, a governance-based trading strategy that focuses on firms in the top HHI tercile earns a monthly alpha of $1.47 \%$, which is more than twice the alpha reported in GIM.

In Panel (C), we report the abnormal returns for equally-weighted portfolios. As in GIM, all results are weaker. For equally-weighted portfolios, GIM find that the Democracy-Dictatorship hedge portfolio earns a monthly alpha of $0.45 \%(t=2.05)$. When replicating their results (excluding companies with missing SIC codes), we obtain an alpha of $0.48 \%(t=2.19)$ (not reported in Table II). Importantly, the basic pattern across HHI groups is similar to that in

\footnotetext{
${ }^{16}$ The alpha and factor loadings are, however, identical to those in Core, Guay, and Rusticus (2006, p. 682).

${ }^{17}$ The Democracy and Dictatorship portfolios in GIM include 572 companies. Excluding companies with missing SIC codes leaves us with 564 companies.

${ }^{18}$ We obtain similar results if we form hedge portfolios based on four HHI groups. The alphas are monotonic in the HHI and only significant in the highest two HHI quartiles. As remarked previously, we use HHI terciles as our benchmark partition to ensure that each portfolio contains sufficiently many companies.
} 
Panel (B). If we form hedge portfolios based on two HHI groups, we find that the alpha is small and insignificant in the below-median HHI group, while it is large and significant in the abovemedian HHI group. The picture is similar if we form hedge portfolios based on three HHI groups. The alpha is small $(0.28 \%)$ and insignificant in the lowest HHI tercile, it is larger $(0.42 \%)$ and (still) insignificant in the medium HHI tercile, and it is largest $(0.72 \%)$ and significant $(t=2.38)$ in the highest HHI tercile.

A valid question is whether the significant alphas in the highest HHI tercile are driven by industry effects and not by corporate governance. While we will investigate this issue in more detail below, let us already notice here that this is rather unlikely. Recall from Panel (A) of Table I that the various Democracy-Dictatorship hedge portfolios based on individual HHI groups are both long and short in firms with almost identical HHIs. ${ }^{19}$ By construction, any direct effect of the HHI on abnormal returns should thus "cancel out". Not surprisingly, when we compute abnormal returns using a five-factor model that includes the HHI as a risk factor, we find that our results remain virtually unchanged (see below). Alternatively, "industry effects" could also come from a clustering of Democracy and Dictatorship firms in industries with high and low abnormal returns, respectively, where the industry return is unrelated to the HHI. In this case, however, it is not clear why the effect would be monotonic in the HHI and insignificant in the lowest HHI tercile. We will address this issue below using industry-adjusted abnormal returns.

\section{Robustness}

Table III contains various robustness checks. In each row of the table, we first report the abnormal return to the Democracy-Dictatorship hedge portfolio based on the entire sample, followed by the abnormal returns to the Democracy-Dictatorship hedge portfolios based on individual HHI groups. We report the results both for value-weighted and equally-weighted portfolios. For ease of comparison, we restate our main results from Table II in row [1].

In rows [2] to [4], we consider alternative measures of product market competition. In row [2], we use the four-firm concentration ratio based on the $48 \mathrm{FF}$ industries. As is shown, the results are similar to those in row [1]. Since the competition measures in rows [1] and [2] are computed from Compustat, they only include publicly traded companies. In row [3], we use instead the HHI provided by the Census Bureau, which includes all public and private firms in the U.S. Unfortunately, this measure is only available for manufacturing industries, which

\footnotetext{
${ }^{19}$ Table I sorts firms into HHI quintiles. However, we obtain similar results if we sort firms into HHI terciles.
} 
means we lose about half of our sample. By construction, smaller portfolios are more volatile. Hence, we would expect the statistical significance of our results to become weaker, especially in the (smaller) hedge portfolios based on individual HHI groups. For value-weighted portfolios, we find that the Democracy-Dictatorship hedge portfolio based on the entire sample earns a monthly alpha of $0.93 \%(t=2.42)$. When we form Democracy-Dictatorship hedge portfolios based on individual HHI groups, we obtain the same picture as before. The alpha is small $(0.02 \%)$ and insignificant in the lowest HHI tercile, it is larger (0.69\%) and (still) insignificant in the medium HHI tercile, and it is largest $(1.50 \%)$ and significant $(t=2.46)$ in the highest HHI tercile. The results are similar for equally-weighted portfolios. In row [4], we use the four-firm concentration ratio provided by the Census Bureau, which again includes all public and private firms in the U.S., albeit only in manufacturing industries. As is shown, the results are similar to those in row [3].

In rows [5] and [6], we consider alternative measures of corporate governance. In row [5], we use the E-index by Bebchuk, Cohen, and Ferrell (2005). The authors argue that the six provisions included in the E-index are the key drivers behind GIM's results. Accordingly, the E-index might be a less noisy proxy of corporate governance. If this is so, we would expect the statistical significance of our results to become stronger. For value-weighted portfolios, we find that the Democracy-Dictatorship hedge portfolio based on the entire sample earns a monthly alpha of $0.74 \%(t=4.09)$. When we form Democracy-Dictatorship hedge portfolios based on individual HHI groups, the picture is again similar to before. The alpha is small $(0.02 \%)$ and insignificant in the lowest HHI tercile, it is larger $(0.84 \%)$ and significant $(t=2.92)$ in the medium HHI tercile, and it is largest $(1.53 \%)$ and significant $(t=3.42)$ in the highest HHI tercile. The results are similar for equally-weighted portfolios. In row [6], we use the ATI by Cremers and Nair (2005). While the G- and E-indices are often interpreted as measures of takeover protection, the ATI truly warrants this interpretation. Besides the fact that the alphas are smaller, the picture is again similar to before.

In rows [7] and [8], we revisit Cremers and Nair's (2005) finding that the DemocracyDictatorship hedge portfolio earns a significant alpha only when institutional ownership is high. Using the same proxy for institutional ownership as they do, namely, the percentage of shares held by the 18 largest public pension funds (PP), we first divide both the Democracy and Dictatorship portfolio each into equal-sized portfolios based on whether PP lies above or below the 
median. $^{20}$ We subsequently divide each of the resulting portfolios into equal-sized portfolios based on HHI terciles. This leaves us with $2 \times 2 \times 3=12$ portfolios: one Democracy portfolio and one Dictatorship portfolio for each PP-HHI group. For each such group, we then construct a hedge portfolio that is long in the respective Democracy portfolio and short in the respective Dictatorship portfolio. Doubling the number of hedge portfolios reduces the number of firms in each portfolio, making the portfolios more volatile. Accordingly, we would expect the statistical significance of our results to become weaker. We obtain four main results. First, the Democracy-Dictatorship hedge portfolio based on the entire sample earns a significant alpha only when institutional ownership is high $(0.77 \%, t=3.02)$. Second, both in the entire sample and in each HHI tercile individually, the alpha is always larger when institutional ownership is high. Both findings are consistent with Cremers and Nair's results. Third, for a given level of institutional ownership, the alpha is monotonically increasing in the HHI, which is consistent with our previous findings. Fourth, and also consistent with our previous findings, when institutional ownership is high, the alpha is only significant in the medium $(0.86 \%, t=2.06)$ and highest $(1.60 \%, t=3.36) \mathrm{HHI}$ terciles. Likewise, when institutional ownership is low, the alpha is only significant in the highest HHI tercile $(0.93 \%, t=1.70)$. The results for equally-weighted portfolios are qualitatively similar, except that the differences between high and low institutional ownership are less pronounced. ${ }^{21}$ Overall, this suggests that our findings and Cremers and Nair's results are not mutually exclusive, but rather that they co-exist in the data.

In row [9], we exclude "new economy" firms as classified by Hand (2003). Core, Guay, and Rusticus (2006) argue that GIM's results are partly driven by these firms. When excluding these firms, the authors find that the alpha of the value-weighted Democracy-Dictatorship hedge portfolio drops to $0.46 \%(t=1.83)$. In our sample, the (average) alpha drops to $0.43 \%(t=$ 1.71). However, when we form Democracy-Dictatorship hedge portfolios based on individual

\footnotetext{
${ }^{20}$ The list of the 18 largest pension funds is provided in the Appendix of Cremers and Nair (2005). The data source is CDA Spectrum. Holdings are reported in March, June, September, and December of each year. To incorporate holdings information into our trading strategies, we rebalance all portfolios in April, July, October, and January using the holdings of the previous quarter. Cremers and Nair also use another proxy for institutional ownership, namely, the percentage of shares held in each firm by the firm's largest institutional blockholder. We obtain similar results when using this alternative proxy.

${ }^{21}$ This is consistent with Panel (B) of Table III in Cremers and Nair (2005), where the alphas for equallyweighted portfolios in the lowest and highest PP groups are almost identical, albeit, like here, their statistical significance is higher when institutional ownership is high.
} 
HHI groups, the picture is again similar to before. The alpha is small $(0.27 \%)$ and insignificant in the lowest HHI tercile, it is larger $(0.41 \%)$ and (still) insignificant in the medium HHI tercile, and it is largest $(0.82 \%)$ and significant $(t=2.04)$ in the highest HHI tercile. ${ }^{22}$ The results are similar for equally-weighted portfolios.

In row [10], we extend the sample period until December $2006 .{ }^{23}$ For value-weighted portfolios, Core, Guay, and Rusticus (2006) find that when the original sample period in GIM is extended until December 2004, the alpha drops to $0.40 \%(t=1.68) \cdot{ }^{24}$ Similarly, if we extend the sample period until December 2006, the alpha drops to $0.24 \%(t=1.22)$ for value-weighted portfolios and to $0.29 \%(t=1.77)$ for equally-weighted portfolios. Note that these findings are not inconsistent with the idea that corporate governance matters for equity returns. After all, it could be that the Democracy-Dictatorship hedge portfolio keeps performing well in the highest HHI tercile, while higher noise in the other two terciles drives the average performance towards a small (and sometimes insignificant) alpha. Indeed, when we consider Democracy-Dictatorship hedge portfolios based on individual HHI groups, this is precisely what we find. For valueweighted portfolios, the alpha is small $(0.06 \%)$ and insignificant in the lowest HHI tercile, it is larger $(0.09 \%)$ and (still) insignificant in the medium HHI tercile, and it is largest $(0.99 \%)$ and significant $(t=2.55)$ in the highest HHI tercile. The results for equally-weighted portfolios are similar.

In row [11], we focus on the post-GIM period after 1999. For value-weighted portfolios, Core, Guay, and Rusticus (2006) find a negative $(-0.13 \%)$ and insignificant alpha for the sub-period from January 2000 to December 2004. Similarly, when we focus on the sub-period from January 2000 to December 2006 , we obtain a negative alpha of $-0.21 \%$ for value-weighted portfolios and a positive alpha of $0.20 \%$ for equally-weighted portfolios. Both alphas are insignificant. However, when we form Democracy-Dictatorship hedge portfolios based on individual HHI groups, we

\footnotetext{
${ }^{22}$ As an alternative to excluding the Internet firms identified by Hand (2003), Core, Guay, and Rusticus (2006) exclude all firms in 2-digit SIC industries that are related to the "new economy" (SIC codes 35, 36, 38, and 73). We obtain similar results when using this alternative method.

${ }^{23}$ We rebalance all portfolios in November 1999, January 2002, January 2004, and January 2006, which are the months after which new IRRC data became available. We additionally rebalance all portfolios each July to incorporate new values of the HHI.

${ }^{24}$ Similarly, Cremers and Nair (2005) find that the annual alpha drops to $7.5 \%$ (from $8.5 \%$ ) if the original sample period in GIM is extended until December 2001.
} 
obtain the same picture as before. The alpha is again monotonically increasing in the HHI both for value- and equally-weighted portfolios, albeit in the highest HHI tercile it is only significant for equally-weighted portfolios $(0.88 \%, t=2.24)$. The latter result deserves closer investigation. It could be that the insignificant alpha for value-weighted portfolios is due to a few bad years for larger firms. Alternatively, it could be that the significant alpha for equally-weighted portfolios is due to a few lucky years for smaller firms. To investigate this issue, we split the post-GIM period into two sub-periods of equal length (January 2000 to June 2003 and July 2003 to December 2006). ${ }^{25}$ Our results (not reported) show that the Democracy-Dictatorship hedge portfolio keeps performing well after 1999. For value-weighted portfolios, the alpha in the highest HHI tercile is insignificant only in the first sub-period, while it is large and significant $(1.44 \%, t=2.44)$ in the second sub-period. For equally-weighted portfolios, the alpha in the highest HHI tercile is large and significant both in the first $(1.12 \%, t=1.67)$ and second $(0.93 \%, t=2.03)$ sub-period. The alphas in the other HHI terciles are insignificant, both for value- and equally-weighted portfolios.

\section{Industry Effects}

It could be that our results are not driven by corporate governance, but rather that they reflect a direct effect of competition on stock returns. Precisely, the worry is that Democracy and Dictatorship firms cluster along industries with different HHIs. For instance, if firms in the highest HHI tercile of the Democracy portfolio had on average lower HHIs than firms in the highest HHI tercile of the Dictatorship portfolio, and if competition had a positive direct effect on stock returns, then this could potentially explain our results. We have already argued why this is rather unlikely. As is shown in Panel (A) of Table I, the empirical distribution of the HHI among Democracy and Dictatorship firms is virtually identical. Accordingly, the DemocracyDictatorship hedge portfolio in the highest (or any other) HHI tercile is both long and short in firms with almost identical HHIs, implying that, by construction, any direct effect of the HHI on abnormal returns should "cancel out".

Table IV addresses this issue in a more rigorous fashion. In a recent paper, Hou and Robinson (2006) document that product market competition, as measured by the HHI, has a direct effect on stock returns even after controlling for the usual four risk factors. To capture this effect, the authors construct an additional risk factor, the "concentration premium" $\lambda^{H}$, by

\footnotetext{
${ }^{25}$ Splitting the post-GIM period into more than two sub-periods is problematic. Already with two sub-periods, the sample length per sub-period is only 48 months, making statistical inferences difficult.
} 
running monthly cross-sectional regressions of individual stock returns on a constant, the HHI, size (in logs), book-to-market (in logs), leverage, the post-ranking beta as defined in Fama and French (1992), and the past one-year stock return (momentum). The concentration premium in month $t$ is the estimated coefficient on the HHI. ${ }^{26}$

To examine if our results are driven by a direct effect of competition on stock returns, we augment equation (1) by including the Hou-Robinson concentration premium as an additional risk factor. That is, we estimate the five-factor model

$$
R_{t}=\alpha+\beta_{1} \times R M R F_{t}+\beta_{2} \times S M B_{t}+\beta_{3} \times H M L_{t}+\beta_{4} \times U M D_{t}+\beta_{5} \times \lambda_{t}^{H}+\varepsilon_{t},
$$

where $R_{t}, R M R F_{t}, S M B_{t}, H M L_{t}$, and $U M D_{t}$ are defined as above, and where $\lambda_{t}^{H}$ is the Hou-Robinson concentration premium. If our results are driven by a direct effect of competition on stock returns, then we would expect the alpha to become insignificant when competition is added as a risk factor. The results are shown in row [2]. For ease of comparison, we restate our main results from Table II in row [1]. As can be seen, the alphas in rows [1] and [2] are identical, both for value- and equally weighted portfolios. Moreover, the concentration premium itself is not significant (not reported). This result is not inconsistent with Hou and Robinson's finding that competition has a direct effect on stock returns. Rather, as explained above, it reflects the fact that the Democracy-Dictatorship hedge portfolio already fully accounts for this direct effect by construction.

Competition is not the only possible source of abnormal industry returns. It could be that Democracy and Dictatorship firms cluster along industries with high and low abnormal returns, respectively, where the abnormal return is driven by industry attributes other than the HHI. In this case, however, it is not clear why the alpha would be monotonic in the HHI and insignificant in the lowest HHI tercile. To address this issue, we re-estimate equation (1) using industryadjusted returns. In each month, we compute the median industry return in a given FF industry using all firms in the merged Compustat/CRSP database and subtract it from the individual stock return. The results are presented in row [3]. The alpha is again small $(0.38 \%)$ and insignificant in the lowest HHI tercile, it is larger (0.49\%) and (still) insignificant in the medium HHI tercile, and it is largest $(1.15 \%)$ and significant $(t=2.72)$ in the highest HHI tercile. The results for equally-weighted portfolios are similar. In row [4], we use again industry-adjusted

\footnotetext{
${ }^{26} \mathrm{Hou}$ and Robinson (2006) compute the HHI based on 3-digit SIC industries. We use the 48 FF industries for internal consistency. However, we obtain similar results when using 3-digit SIC industries.
} 
returns, though now in conjunction with the five-factor model in equation (2), which includes competition as an additional risk factor. The alphas are virtually identical to those in row [3], both for value- and equally weighted portfolios. This is not surprising. Since the DemocracyDictatorship hedge portfolio already fully controls for any direct effect of competition, it should make little difference if we use the model in equation (1) or equation (2).

\subsection{Fama-MacBeth Return Regressions}

It is possible that the abnormal returns to the Democracy-Dictatorship hedge portfolio are driven by an omitted variable bias. Such a bias could arise if the G-index is correlated with firm characteristics that were priced during the sample period but that are not captured by the model in equation (1). To address this concern, GIM estimate Fama-MacBeth regressions that include a broad array of control variables. We augment GIM's specification in two ways. First, to examine whether governance has a different effect on stock returns in competitive and non-competitive industries, we interact it with the HHI. Second, we include additional controls. For each month, we estimate the cross-sectional regression

$$
r_{i t}=\alpha_{t}+\boldsymbol{\beta}_{t}^{\prime}\left(G_{i t} \times \mathbf{I}_{i t}\right)+\gamma_{t}^{\prime} \mathbf{X}_{i t}+\varepsilon_{i t},
$$

where $r_{i t}$ is the return on firm $i$ 's stock in month $t, G_{i t}$ is either the G-index or a Democracy dummy, $\mathbf{I}_{i t}$ is a $(3 \times 1)$ vector of HHI dummies, and $\mathbf{X}_{i t}$ is a vector of control variables. All right-hand side variables are lagged. The HHI dummies indicate whether the HHI of firm $i$ in month $t$ lies in the lowest, medium, or highest tercile of its empirical distribution. We estimate equation (3) for each month and calculate the mean and time-series standard deviation of the 112 monthly estimates to obtain the Fama-MacBeth coefficients and standard errors.

As elements of $\mathbf{X}$, we include the full set of controls used in GIM: firm size, book-to-market ratio, stock price, return from months $t-3$ to $t-2$, from months $t-6$ to $t-4$, and from months $t-12$ to $t-7$, respectively, (dollar) trading volume of NYSE or AMEX stocks, (dollar) trading volume of NASDAQ stocks, a NASDAQ dummy, an S\&P 500 dummy, dividend yield, sales growth over the previous five fiscal years, and institutional ownership. A detailed description of all of these variables is provided in GIM. To control for any direct effect of competition on stock returns (see previous section), we also include HHI dummies. Finally, we include a proxy for idiosyncratic volatility. In a recent paper, Ferreira and Laux (2007) show that firms with fewer antitakeover provisions display higher levels of idiosyncratic volatility. This could have pricing 
implications. We proxy for idiosyncratic volatility using the Ferreira-Laux measure

$$
\Psi_{i t}=\ln \left(\frac{1-R_{i t}^{2}}{R_{i t}^{2}}\right)
$$

where $R_{i t}^{2}$ is the R-squared from the monthly regression $r_{i d t}=\alpha_{i t}+\beta_{i t} \times r_{m d t}+\varepsilon_{i d t}$, in which $r_{i d t}$ and $r_{m d t}$ are the excess return on stock $i$ and the value-weighted CRSP market index, respectively, on day $d$ in month $t$. In the cross-sectional regression in month $t$, we include as a control variable the idiosyncratic volatility in month $t-1$.

The results are presented in Table V. In columns [1] and [2], we proxy for governance using the G-index. In columns [3] and [4], we use the Democracy dummy as our governance proxy while restricting the sample to Democracy and Dictatorship firms. In columns [1] and [3], governance is not interacted with competition. Thus, except for the inclusion of the HHI and idiosyncratic volatility as additional controls, these regressions mirror those in GIM. The regressions in columns [2] and [4] are those depicted in equation (3). For brevity's sake, we only report the coefficients on $G$ and $G \times \mathbf{I}$, which are our main variables of interest.

In column [1], the coefficient on the (non-interacted) G-index is small (-0.04) and insignificant, although it has the right sign. As GIM note, the coefficient on the G-index can be interpreted as a monthly abnormal return. Thus, on average, the monthly abnormal return associated with the G-index is a mere $0.04 \%$, which is identical to the number in GIM. In column [2], the G-index is interacted with the HHI. As is shown, the coefficient on the G-index is monotonic in the HHI, but it is again small in magnitude. Even in the highest HHI tercile, the coefficient on the G-index is only $-0.12(t=1.93)$, which corresponds to a monthly abnormal return of only $0.12 \%$. The results are markedly different if we proxy for governance using the Democracy dummy. In column [3], the coefficient on the (non-interacted) Democracy dummy is $0.77(t=2.43)$, which is close to the number in $\operatorname{GIM}(0.76, t=2.38)$. In column [4], the Democracy dummy is interacted with the HHI. As is shown, the coefficient on the Democracy dummy is small (0.24) and insignificant in the lowest HHI tercile, it is larger (1.00) and marginally significant $(t=1.72)$ in the medium HHI tercile, and it is largest (1.77) and significant $(t=2.52)$ in the highest HHI tercile.

That all results are stronger if we use the Democracy dummy does not surprise. As is typically the case with equity returns, the effect can only be found in the extremes. Accordingly, and consistent with the idea behind the construction of the Democracy-Dictatorship hedge portfolio, if one wants to find an effect of governance on stock returns, one must consider extreme values 
of governance, like those associated with Democracy and Dictatorship firms.

\subsection{Analysts' Earnings Forecasts}

There are two potential explanations for the abnormal returns earned by the DemocracyDictatorship hedge portfolio. One is an omitted variable bias. Such a bias could arise if governance provisions are correlated with firm or other characteristics that were priced during the sample period but that are not captured by the asset pricing model used to calculate abnormal returns. In the previous section, and consistent with GIM's own findings, we found no evidence for this hypothesis. The alternative explanation is that weak governance gives rise to agency costs whose magnitude was underestimated by investors. Consistent with the first part of this hypothesis, GIM find that weak governance is associated with both higher capital expenditures and higher acquisition activity. Likewise, Core, Guay, and Rusticus (2006) and GIM both find that weak governance is associated with lower operating performance. However, Core, Guay, and Rusticus find no evidence for the second part of the hypothesis, namely, that investors were surprised. The authors test whether the stock market underperformance of weak governance firms is due to investor surprise about the poor operating performance of these firms. Using analysts' earnings forecasts to proxy for investors' expectations, they find no significant relation between forecast errors and governance proxies.

Given our previous results, a natural question is whether analysts correctly predict that governance has a different effect in competitive and non-competitive industries. Following Core, Guay, and Rusticus, we use analysts' earnings forecasts to proxy for investors' expectations. The data on analysts' forecasts are obtained from the Institutional Brokers' Estimate System (I/B/E/S). Our main measure is the mean I/B/E/S consensus forecast of annual earnings per share (EPS), measured 8 months prior to the fiscal year's end. We will use median I/B/E/S consensus forecasts in robustness checks. Measuring analysts' forecasts 8 months (instead of 12 months) before the fiscal year's end ensures that the analysts know the previous year's earnings when making their forecasts. Analysts' forecasts are scaled by lagged total assets per share, where total assets is the book value of total assets (Compustat item \#6) in the previous fiscal year, and where the number of shares in the month of the forecast is taken from CRSP. ${ }^{27}$ To

\footnotetext{
${ }^{27}$ Core, Guay, and Rusticus (2006) also use the mean I/B/E/S consensus forecast of annual EPS measured 8 months prior to the fiscal year's end and scale it by either lagged total assets per share or by the lagged share price. We obtain similar results when using the latter scaling method.
} 
mitigate the effect of outliers and coding errors, we remove observations for which the forecast error is larger than $10 \%$ of the share price in the month of the forecast (less than $3 \%$ of the sample). ${ }^{28}$ Moreover, to ensure that the consensus forecasts are reliable proxies of market expectations, we require that a company is followed by at least five analysts. ${ }^{29}$

We estimate the equation

$$
y_{i t}=\alpha_{j}+\alpha_{t}+\boldsymbol{\beta}^{\prime}\left(G_{i t-1} \times \mathbf{I}_{i t-1}\right)+\boldsymbol{\gamma}^{\prime} \mathbf{X}_{i t-1}+\varepsilon_{i t},
$$

where $y_{i t}$ is either the mean (median) I/B/E/S consensus forecast of annual EPS, the actual I/B/E/S annual EPS, or the forecast error (actual I/B/E/S annual EPS minus mean (median) I/B/E/S consensus forecast of annual EPS), all scaled down by lagged total assets per share, for firm $i$ in year $t, \alpha_{j}$ and $\alpha_{t}$ are industry- and year-fixed effects, $G_{i t-1}$ is a 1-year lagged Democracy dummy, $\mathbf{I}_{i t-1}$ is a $(3 \times 1)$ vector of 1-year lagged HHI dummies, and $\mathbf{X}_{i t-1}$ is a vector of control variables. As controls, we include 1-year lagged HHI dummies, 1-year lagged book-to-market ratio, and 1-year lagged firm size. To allow the book-to-market ratio and firm size to have different effects across HHI terciles, we interact each of these variables with 1-year lagged HHI dummies. Firm size is the logarithm of the book value of total assets (Compustat item \#6). The book-to-market ratio is computed as the logarithm of the ratio of the market value of equity (item \#199 $\times$ item \#25) over the book value of equity (item \#60 + item \#74). The sample is restricted to Democracy and Dictatorship firms and ranges from 1991 to 1999. Standard errors are clustered at the industry level. ${ }^{30}$

The results are presented in Table VI. Panel (A) considers mean I/B/E/S consensus forecasts, while Panel (B) considers median I/B/E/S consensus forecasts. For brevity's sake, we only discuss Panel (A). The results in Panel (B) are virtually identical. As in the previous section, we show first the results for the non-interacted Democracy dummy (columns [1] to [3]), followed by the results for when the Democracy dummy is interacted with HHI dummies (columns [4]

\footnotetext{
${ }^{28}$ See, e.g., Easterwood and Nutt (1999), Lim (2001), and Teoh and Wong (2002).

${ }^{29}$ See, e.g., Mikhail, Walther, and Willis (1999), Easterwood and Nutt (1999), and Loha and Mianc (2006).

${ }^{30}$ Core, Guay, and Rusticus (2006) use the Fama-MacBeth method while accounting for serial correlation using the Newey-West procedure with one lag. Given that both the dependent and independent variables are persistent, the Fama-MacBeth method produces biased standard errors even if combined with the Newey-West procedure (Petersen (2007)). To address this bias, we estimate a panel with fixed effects and clustered standard errors. The choice of industry- rather than firm-fixed effects is due to insufficient within-variation of the G-index (see Section 4 below and p. 126 in GIM).
} 
to [6]). For brevity's sake, we only report the coefficients on $G$ and $G \times \mathbf{I}$, which are our main variables of interest. All coefficients are multiplied by 100 .

Columns [1] and [2] show that Democracy firms exhibit on average higher EPS than Dictatorship firms, and that analysts correctly predict this outcome. The forecast error, which is reported in column [3], is small and insignificant. Based on this result, Core, Guay, and Rusticus conclude that investors were not surprised. Columns [4] to [6] paint a more nuanced picture. Column [4] shows that Democracy firms exhibit significantly higher EPS only when competition is weak. While the difference in (actual) EPS between Democracy and Dictatorship firms is small and insignificant in the lowest and medium HHI terciles, it is large and significant in the highest HHI tercile. Second, and this is remarkable, analysts seem to understand that governance has an effect on EPS only in non-competitive industries. As column [5] shows, the difference in forecasted EPS between Democracy and Dictatorship firms is small and insignificant in the lowest and medium HHI terciles, while it is large and significant in the highest HHI tercile. However, analysts seem to underestimate the magnitude of the effect of governance in non-competitive industries. While the forecast error in column [6] is small and insignificant in the lowest and medium HHI terciles, it is positive and significant in the highest HHI tercile. Thus, analysts underestimate the effect of governance on EPS in precisely those industries in which governance matters for EPS. Whether the forecast error is large enough to fully explain the abnormal returns in GIM is an open question. At a minimum, it provides evidence in support of the hypothesis that investors were surprised, which is consistent with GIM's own interpretation of their findings.

\section{Firm Value and Operating Performance}

To provide further evidence on the role of governance, GIM examine the relation between governance and firm value (Tobin's Q) and between governance and operating performance (net profit margin, return on equity, sales growth). Core, Guay, and Rusticus (2006) extend GIM's results by examining the relation between governance and return on assets. In this section, we investigate whether the relation between governance and either firm value or operating performance is different in competitive and non-competitive industries. We first consider Tobin's Q. In the next section, we consider return on assets, net profit margin, and return on equity. ${ }^{31}$

\footnotetext{
${ }^{31}$ The results for sales growth are similar to those of the other performance measures.
} 


\subsection{Corporate Governance and Firm Value}

\section{Main Results}

Tobin's Q is computed using the same definition as in GIM. Tobin's Q is the market value of assets divided by the book value of assets (Compustat item \#6), where the market value of assets is the book value of assets plus the market value of common stock (item $\# 24 \times$ item \#25) minus the sum of the book value of common stock (item \#60) and balance sheet deferred taxes (item \#74). Following GIM, we compute industry-adjusted Tobin's Q by subtracting the industry median in a given FF industry and year. Industry medians are computed using all firms in the Compustat universe. The sample period is from 1990 to $2006 .^{32}$

As in GIM, we first estimate Fama-MacBeth regressions of industry-adjusted Q on the Gindex (or the G-index interacted with HHI dummies) and controls. This method has been criticized for producing biased standard errors when both the dependent and independent variables are persistent (Petersen, 2007). To address this bias, we will re-estimate our results using a panel with fixed effects and clustered standard errors.

For each year, we estimate the cross-sectional regression

$$
Q_{i t}^{*}=\alpha_{t}+\boldsymbol{\beta}_{t}^{\prime}\left(G_{i t} \times \mathbf{I}_{i t}\right)+\gamma_{t}^{\prime} \mathbf{X}_{i t}+\varepsilon_{i t}
$$

where $Q_{i t}^{*}$ is the industry-adjusted $\mathrm{Q}$ of firm $i$ in year $t, G_{i t}$ is the G-index, $\mathbf{I}_{i t}$ is a $(3 \times 1)$ vector of HHI dummies, and $\mathbf{X}_{i t}$ is a vector of control variables. ${ }^{33}$ We estimate equation (5) for each year separately and calculate the mean and time-series standard deviation of the yearly estimates to obtain the Fama-MacBeth coefficients and standard errors. As elements of $\mathbf{X}$, we include the full set of controls used in GIM: firm size, which is the logarithm of the book value of total assets (Compustat item \#6), firm age (in logs), an S\&P 500 dummy, and a Delaware dummy. To control for any direct effect of competition, we also include HHI dummies. Moreover, to

\footnotetext{
${ }^{32}$ In Section 3, where we considered stock returns, we used the original sample period in GIM (1990 to 1999) to make our results comparable to theirs. In the case of Tobin's Q, GIM estimate cross-sectional regressions for each year separately. Thus, we can extend the sample period while still comparing our results to GIM's original results for the years 1990 to 1999.

${ }^{33}$ When we examined the performance of governance-based trading strategies, we restricted the sample to Democracy and Dictatorship firms. This is because, as is typically the case with equity returns, the effect could only be found in the extremes. In the case of Tobin's Q, such a restriction is not necessary, which means we can use the full sample and the G-index as our governance proxy.
} 
allow the control variables to have different effects across HHI terciles, we interact each of them with HHI dummies. For brevity's sake, we only report the coefficients on $G$ and $G \times \mathbf{I}$, which are our main variables of interest.

The results are presented in Table VII. Each row refers to a different year. The FamaMacBeth coefficients are reported in the last row. As previously, we estimate equation (5) first without and then with HHI dummies. Column [1] shows the coefficient on $G$ in the regression without HHI dummies. This regression is identical to the specification in GIM. Columns [2] to [4] show the coefficients on $G \times \mathbf{I}$ in the regressions with HHI dummies.

As is shown in column [1], the coefficient on the (non-interacted) G-index is always negative and almost always significant (14 out of 17 years). The estimates for the years 1990 to 1999 mirror the findings in GIM. ${ }^{34}$ The estimates for the years after 1999 are similar. Thus, unlike the abnormal returns to the Democracy-Dictatorship hedge portfolio, the negative relation between firm value and the G-index does not weaken after 1999. In the last row, the Fama-MacBeth coefficient for the years 1990 to 2006 is $-0.040(t=6.10)$, which is similar to what GIM have found for the years 1990 to $1999(-0.043, t=4.78)$.

As columns [2] to [4] show, the basic pattern across HHI terciles is similar to what we have found in the case of equity returns. The coefficient on the G-index is monotonic in the HHI in the majority of years (13 out of 17 years), it is always small and insignificant in the lowest HHI tercile, and it is always negative, economically large, and almost always significant (16 out of 17 years) in the highest HHI tercile. In some years, it is also significant in the medium HHI tercile. The Fama-MacBeth coefficients in the last row reflect this pattern. The Fama-MacBeth coefficient is small $(-0.004)$ and insignificant in the lowest HHI tercile, it is larger $(-0.047)$ and significant $(t=4.66)$ in the medium HHI tercile, and it is largest $(-0.073)$ and significant $(t=7.36)$ in the highest HHI tercile.

As in the context of equity returns, our results can be interpreted in two ways. One interpretation is that governance has no effect on firm value in competitive industries. The other interpretation, which is merely the other side of the coin, is that governance has a strong effect on firm value in non-competitive industries. In those industries, the effect of governance is almost twice as large as what has been reported in GIM, who show the average effect across all

\footnotetext{
${ }^{34}$ The coefficients are close but not identical to those in GIM due to small differences in industry adjustments. While GIM assign firms to FF industries using the SIC codes from CRSP, we use the SIC codes from Compustat for internal consistency, since our HHI measure is computed using sales from Compustat.
} 
industries.

As we have already remarked above, the statistical significance of the Fama-MacBeth coefficients must be interpreted with caution. In a simulation-based study, Petersen (2007) shows that the Fama-MacBeth standard errors will be biased downwards if both the left- and right-hand side variables are persistent. In Table VII, the $t$-statistics associated with the Fama-MacBeth coefficients are arguably very large, especially since they are only based on 17 annual coefficients. For instance, the $t$-statistic in the lowest HHI tercile is 1.01 even though the coefficient itself is close to zero. Note also that the coefficients in the lowest HHI tercile are all negative until the year 2000, after which they become all positive (except for the year 2004, where the coefficient is virtually zero). This is suspicious given that the coefficients in the lowest HHI tercile are small and not statistically different from zero, in which case, had they been random draws, their signs should be erratic and not follow any specific pattern.

As an alternative to using the Fama-MacBeth method, Petersen (2007) advocates the use of a pooled panel with clustered standard errors. We will adopt this approach both in this and the following section, where we estimate performance regressions plagued by similar (persistence) problems. Throughout, we cluster standard errors at the industry level. ${ }^{35}$ Moreover, we include both industry- and year-fixed effects. The use of industry- rather than firm-fixed effects is due to insufficient within-variation of the G-index, a point that has already been made by GIM (p. 126). In robustness checks, we will use firm- instead of industry-fixed effects, mindful of the limitation that the identification of the main coefficients comes from relatively rare changes of the G-index.

We estimate the equation

$$
Q_{i t}^{*}=\alpha_{j}+\alpha_{t}+\boldsymbol{\beta}^{\prime}\left(G_{i t} \times \mathbf{I}_{i t}\right)+\gamma^{\prime} \mathbf{X}_{i t}+\varepsilon_{i t},
$$

where $Q_{i t}^{*}, G_{i t}, \mathbf{I}_{i t}$, and $\mathbf{X}_{i t}$ are defined as above, and where $\alpha_{j}$ and $\alpha_{t}$ are industry- and yearfixed effects, respectively.

The results are presented in Table VIII. The estimate in column [1] is the counterpart of the Fama-MacBeth estimate in column [1] of Table VII. Likewise, the estimates in column

\footnotetext{
${ }^{35}$ Clustering standard errors at the industry level accounts for arbitrary correlations of the error terms i) across different firms in a given industry and year (cross-sectional correlation), ii) across different firms in a given industry over time (across-firm serial correlation), and iii) within the same firm over time (within-firm serial correlation). Clustering by industry is thus more general than, e.g., clustering by either firm or industry-year.
} 
[2] are the counterparts of the Fama-MacBeth estimates in column [2] to [4] of Table VII. As can be seen, the coefficients in both tables are very similar. In column [1], the coefficient on the (non-interacted) G-index is $-0.036(t=3.46)$, while the corresponding Fama-MacBeth coefficient is $-0.040(t=6.10)$. Likewise, in columns [2] to [4], the coefficient on the G-index in the lowest, medium, and highest HHI tercile is $-0.003(t=0.32),-0.044(t=2.03)$, and $-0.067(t=3.37)$, respectively, while the corresponding Fama-MacBeth coefficients are -0.004 $(t=1.01),-0.047(t=4.66)$, and $-0.073(t=7.36)$, respectively. As one would expect, the $t$-statistics are all considerably smaller when using clustered standard errors. Nevertheless, the economic interpretation of the results remains the same. While governance has no effect on firm value in competitive industries, it has a strong effect in non-competitive industries. Moreover, since the coefficient on the G-index in the highest HHI tercile is very similar to the corresponding Fama-MacBeth estimate, it also remains true that the effect of governance on firm value in noncompetitive industries is almost twice as large as what has been previously reported by GIM, who document the average effect across all industries.

\section{Robustness}

Table IX contains various robustness checks. In each row of the table, we first report the coefficient on $G$ in the regression without HHI dummies, followed by the coefficients on $G \times \mathbf{I}$ in the regressions with HHI dummies. For ease of comparison, we restate our main results from Table VIII in row [1].

The robustness checks in rows [2] to [7] are analogous to those in Table III, which is why we refer to Section 3.1 for a description of the variables and motivation of the various robustness checks. As is shown, the basic pattern is similar in all rows. The coefficient on the G-index is always monotonic in the HHI, it is always small and insignificant in the lowest HHI tercile, and it is always large and significant in the medium and highest HHI terciles. Interestingly, and in contrast to Table III where we computed abnormal returns to the Democracy-Dictatorship hedge portfolio, the results do not weaken substantially if we exclude "new economy" firms as classified by Hand (2003) (see row [7]).

In row [8], we use non-industry adjusted Tobin's Q. As is shown, the results are virtually unchanged. In row [9], we use firm-fixed effects instead of industry-fixed effects. As we have already remarked, this specification must be interpreted with caution as the identification of the main coefficients comes from relatively rare changes of the G-index. With this qualification in 
mind, it is interesting to note that we obtain again similar results, albeit the coefficients and their statistical significance are weaker. In particular, the basic pattern across HHI terciles is similar to before. The coefficient on the G-index is small (0.003) and insignificant in the lowest HHI tercile, it is larger $(-0.018)$ and (still) insignificant in the medium HHI tercile, and it is largest $(-0.052)$ and significant $(t=2.91)$ in the highest HHI tercile.

In row [10], we use median (least absolute deviation) regressions instead of OLS regressions to account for the presence of outliers. ${ }^{36}$ The main complication introduced by using median regressions in the context of panel data is the computation of the standard errors. If there is cross-sectional and serial dependence within an industry, the asymptotic covariance matrix of Koenker and Bassett (1978), which assumes independent observations, cannot be used. The standard bootstrap approach cannot be used either, because it only corrects for heteroscedasticity. To circumvent this problem, we use a modified bootstrap approach: block bootstrapping. The difference to a standard bootstrapping procedure is that instead of drawing single observations, we draw entire blocks of observations. The idea is to preserve the correlation structure within each block and to use the independence between the blocks to consistently estimate the standard errors. In analogy to the clustering approach that we used in the OLS regressions, we form 48 blocks, that is, one block for each FF industry. Specifically, we construct a large number (200) of bootstrap samples by drawing with replacement 48 industries from our sample. For each bootstrap sample, we estimate our basic specification using the median regression and store the coefficients. For each coefficient $\phi$, we can then construct a confidence interval from the empirical distribution of the sample of bootstrapped coefficients $\left\{\phi_{k}, k=1, \ldots, 200\right\}$, which allows us to compute the $p$-value for the null hypothesis that the coefficient is zero. ${ }^{37}$ The $p$-value is computed as $p=|1-2 n|$, where $n$ is the fraction of the 200 bootstrapped coefficients that are negative.

As is shown in row [10], both the coefficients and their statistical significance are weaker if we use median regressions instead of OLS, which suggests that our previous OLS estimates are partly driven by outliers. Still, the picture is qualitatively similar to before. In the regression without HHI dummies, the coefficient on the (non-interacted) G-index is negative $(-0.007)$ and

\footnotetext{
${ }^{36}$ GIM do not use median regressions in conjunction with Tobin's Q, but they note that their results remain unchanged if they trim the data to account for outliers (footnote 18, p. 126).

${ }^{37}$ This corresponds to the so-called "percentile method," which is recommended by Koenker and Hallock (2000, p. 14) in the context of the median regression.
} 
significant $(p=0.02)$. Likewise, in the regression with HHI dummies, the coefficient on the G-index is small $(-0.001)$ and insignificant in the lowest HHI tercile, it is larger $(-0.013)$ and marginally significant $(p=0.07)$ in the medium HHI tercile, and it is largest $(-0.022)$ and significant $(p=0.00)$ in the highest HHI tercile.

While all coefficients are weaker if we use the median regression, they remain economically significant. For instance, a coefficient of -0.022 in the highest HHI tercile means that adding one (anti-)governance provision (an increase in the G-index by one index point) decreases Tobin's Q by 2.2 percentage points. Adding nine (anti-)governance provisions (e.g., switching from the Democracy cutoff (G-index of 5) to the Dictatorship cutoff (G-index of 14)) decreases Tobin's Q by almost 20 percentage points. We have verified that all results in Table IX are similar if we use median regressions instead of OLS.

\subsection{Corporate Governance and Operating Performance}

We consider three measures of operating performance: return on assets (ROA), net profit margin (NPM), and return on equity (ROE). ROA is arguably the most suited of these measures. NPM is based on firms' sales, which can be very volatile, while ROE depends on firms' leverage. ROA is net income (Compustat item \#172) divided by the book value of total assets (item \#6), NPM is net income divided by sales (item \#12), and ROE is net income divided by the book value of common stock (item \#60). As in the case of Tobin's Q, all of these measures are industryadjusted by subtracting the industry median in a given FF industry and year. Industry medians are computed using all firms in the Compustat universe.

We use the same specification as in equation (6), except that the dependent variable is now either ROA, NPM, or ROE. The sample period is again from 1990 to 2006. Following GIM, we include as an additional control the logarithm of the book-to-market ratio in the previous fiscal year. The book-to-market ratio is computed as the ratio of the book value of common stock (item \#60) plus balance sheet deferred taxes (item \#74) over the market value of common stock (item \#24 $\times$ item \#25). To account for outliers, which is a common occurrence for all three performance measures, we follow GIM and use median (least absolute deviation) regressions in place of OLS. ${ }^{38}$ As we did in row [10] of Table IX, we assess the statistical significance of the

\footnotetext{
${ }^{38}$ In all our regressions, we obtain similar results when using OLS with the dependent variable being trimmed at some reasonable cutoff (e.g., 1\% and 99\%).
} 
coefficients using block bootstrapping (48 blocks and 200 bootstrap samples). For brevity's sake, we only report the coefficients on $G$ and $G \times \mathbf{I}$.

The results are presented in Table $\mathbf{X}$. Columns [1] and [2] show the results with ROA as the dependent variable, columns [3] and [4] show the results with NPM as the dependent variable, and columns [5] and [6] show the results with ROE as the dependent variable. As previously, we estimate each regression first without and then with HHI dummies. The odd-numbered columns show the coefficient on $G$ in the regressions without HHI dummies, while the even-numbered columns show the coefficients on $G \times \mathbf{I}$ in the regressions with HHI dummies. All coefficients are multiplied by 100 for expositional convenience.

As column [1] shows, governance has on average a significant positive effect on ROA. The coefficient on the (non-interacted) G-index is $-0.071(p=0.00)$, which means that adding one (anti-)governance provision (an increase in the G-index by one index point) decreases ROA by 0.071 percentage points. (Recall that all coefficients are multiplied by 100.) This is similar in magnitude to the estimates in Core, Guay, and Rusticus (2006), who find that the marginal effect of an increase in the G-index on ROA is between -0.03 and -0.1 percentage points. ${ }^{39}$ In column [2], the pattern across HHI terciles is similar to what we have found in the case of Tobin's Q. The coefficient on the G-index is again small (-0.006) and insignificant in the lowest HHI tercile, it is larger $(-0.109)$ and significant $(p=0.00)$ in the medium HHI tercile, and it is largest $(-0.140)$ and significant $(p=0.00)$ in the highest HHI tercile.

In column [3], the marginal effect of an increase in the G-index on NPM is $-0.078(p=0.00)$, which is roughly similar to what GIM have found for the years 1990 to $1999(-0.064, t=4.92) .{ }^{40}$ In column [4], the basic pattern across HHI terciles is again similar to before. The coefficient on the G-index is small (-0.031) and insignificant in the lowest HHI tercile, it is larger $(-0.094)$ and marginally significant $(p=0.08)$ in the medium HHI tercile, and it is largest $(-0.117)$ and significant $(p=0.00)$ in the highest HHI tercile.

\footnotetext{
${ }^{39}$ The economic magnitude is also similar to that in Table VI of this paper, which shows that switching from the Dictatorship to the Democracry portfolio increases EPS (scaled by assets per share) by 0.60 percentage points. In Table X, given that a switch from the Dictatorship to the Democracry portfolio implies a decrease in the G-index of approximately 10.22 index points, the associated increase in ROA is about $0.071 \times 10.22 \approx 0.73$ percentage points, which is of a similar order of magnitude.

${ }^{40}$ In GIM, the coefficient on the G-index in the NPM and ROE regressions is -0.64 and -0.26 , respectively (Table IX, last row). However, GIM multiply all coefficients by 1,000, while we multiply all coefficients by 100 .
} 
In column [5], the marginal effect of an increase in the G-index on ROE is -0.015, although the effect is not statistically significant $(p=0.56)$. Again, this is similar to what GIM have found for the years 1990 to $1999(-0.026, t=0.79)$. While the effect of governance on ROE is not significant on average, it is interesting to note that the pattern across HHI terciles is similar to before. In column [6], the coefficient on the G-index is small (0.005) and insignificant in the lowest HHI tercile, it is larger $(-0.032)$ and (still) insignificant in the medium HHI tercile, and it is largest $(-0.085)$ and marginally significant $(p=0.08)$ in the highest HHI tercile.

Overall, the results presented in this section are consistent with those obtained in the context of Tobin's Q and equity returns. While governance appears to matter only little in competitive industries, it has a significant positive effect on operating performance in non-competitive industries. And like in the case of Tobin's Q and equity returns, the effect of governance on operating performance in non-competitive industries is substantially larger than what has been previously documented in either Core, Guay, and Rusticus (2006) or GIM, who both show the average effect across all industries.

\section{Conclusion}

Economists have long argued that managerial incentive problems are first and foremost an issue for firms in non-competitive industries. By implication, firms in competitive industries should benefit relatively less from good governance, while firms in non-competitive industries - where lack of competitive pressure fails to enforce discipline on managers - should benefit relatively more. The evidence presented in this paper supports this hypothesis. Whether we look at stock returns, firm value, or operating performance, we consistently find the same pattern. The effect of governance is always monotonic in the degree of competition, it is always small and insignificant in competitive industries, and it is always large and significant in non-competitive industries. By construction, since the results in GIM and subsequent work document the average effect across all industries, this implies that the effects of governance (in non-competitive industries) reported in this paper are stronger than what has been previously documented. For example, GIM find that a hedge portfolio that is long in firms with good governance and short in firms with bad governance earns a monthly alpha of $0.67 \%$. When we sub-divide the hedge portfolio into three hedge portfolios based on whether competition is low, medium, or high, we find that the hedge portfolio associated with the lowest degree of competition earns a monthly 
alpha of $1.47 \%$, which is approximately twice as large as the alpha reported in GIM.

In some cases, we find that governance has a strong and significant effect in non-competitive industries, while the average effect across all industries is small and insignificant. For example, previous research has shown that the alpha earned by GIM's hedge portfolio all but disappears if the sample period is extended beyond 1999. When we extend the sample period until 2006, we do indeed find that the average alpha is small and insignificant. However, the alpha remains large and significant in non-competitive industries. Likewise, it has been argued that investors in the 1990s fully anticipated the effects of governance, implying that the alpha earned by the hedge portfolio is likely due to an omitted risk factor. Consistent with prior research, we find that on average investors were not surprised. However, investors did underestimate the effect of governance in non-competitive industries, the very industries in which governance matters in the first place. Whether this investor surprise is large enough to fully explain the abnormal returns is an open question. At a minimum, it provides evidence consistent with the notion that investors did not fully anticipate the effects of governance.

Our findings have important implications. On a practical note, our results imply that researchers who want to investigate the effects of governance could benefit from interacting governance with measures of competition. In fact, as shown above, researchers might find that governance has a strong and significant effect in non-competitive industries even if the average effect across all industries is insignificant. Perhaps more important, our results imply that policy efforts to improve corporate governance could benefit from focusing on non-competitive industries. Moreover, such efforts could be broadened to also include policy measures aimed at improving an industry's competitiveness, such as deregulation and antitrust laws.

\section{References}

Alchian, Armen A., 1950, Uncertainty, Evolution, and Economic Theory, Journal of Political Economy 58, 211-221.

Bebchuk, Lucian A., Alma Cohen, and Allen Ferrell, 2005, What Matters in Corporate Governance?, mimeo, Harvard Law School.

Bertrand, Marianne, and Sendhil Mullainathan, 2003, Enjoying the Quiet Life? Corporate Governance and Managerial Preferences, Journal of Political Economy 111, 1043-1075. 
Carhart, Mark M., 1997, On Persistence in Mutual Fund Performance, Journal of Finance 52, $57-82$.

Core, John E., Wayne R. Guay, and Tjomme O. Rusticus, 2006, Does Weak Governance Cause Weak Stock Returns? An Examination of Firm Operating Performance and Investors' Expectations, Journal of Finance 61, 655-687.

Cremers, K. J. Martin, Vinay B. Nair, and Urs Peyer, 2008, Takeover Defenses and Competition, forthcoming in Journal of Empirical Legal Studies.

Cremers, K. J. Martin, and Vinay B. Nair, 2005, Governance Mechanisms and Equity Prices, Journal of Finance 60, 2859-2894.

Curry, Bruce, and Kenneth D. George, 1983, Industrial Concentration: A Survey, Journal of Industrial Economics 31, 203-255.

Easterwood, John C., and Stacey R. Nutt, 1999, Inefficiency in Analysts' Earnings Forecasts: Systematic Misreaction or Systematic Optimism? Journal of Finance 54, 1777-1797.

Fama, Eugene F., and Kenneth R. French, 1992, The Cross-Section of Expected Stock Returns, Journal of Finance 47, 427-465.

Fama, Eugene F., and Kenneth R. French, 1997, Industry Costs of Capital, Journal of Financial Economics 43, 153-193.

Ferreira, Miguel A., and Paul A. Laux, 2007, Corporate Governance, Idiosyncratic Risk, and Information Flow, Journal of Finance 62, 951-989.

Friedman, M., 1953, Essays in Positive Economics. Chicago: University of Chicago Press.

Giroud, Xavier, and Holger M. Mueller, 2008, Does Corporate Governance Matter in Competitive Industries?, mimeo, New York University.

Gompers, Paul A., Joy L. Ishii, and Andrew Metrick, 2003, Corporate Governance and Equity Prices, Quarterly Journal of Economics 118, 107-155.

Hand, John R. M., 2003, Profits, Losses and the Nonlinear Pricing of Internet Stocks, in: Intangible Assets: Values, Measures and Risks, ed. by J. R. M. Hand and B. Lev. Oxford: Oxford University Press. 
Hicks, John R., 1935, Annual Survey of Economic Theory: The Theory of Monopoly, Econometrica $3,1-20$.

Hou, Kewei, and David T. Robinson, 2006, Industry Concentration and Average Stock Returns, Journal of Finance 61, 1927-1956.

Koenker, Roger, and Gilbert Bassett, Jr., 1978, Regression Quantiles, Econometrica 46, 33-50.

Koenker, Roger, and Kevin F. Hallock, 2000, Quantile Regression: An Introduction, mimeo, University of Illinois at Urbana-Champaign.

Lim, Terence, 2001, Rationality and Analysts' Forecast Bias, Journal of Finance 56, 369-385.

Loha, Roger K., and G. Mujtaba Mianc, 2006, Do Accurate Earnings Forecasts Facilitate Superior Investment Recommendations?, Journal of Financial Economics 80, 455-483.

Mikhail, Michael B., Beverly R. Walther, and Richard H. Willis, 1999, Does Forecast Accuracy Matter to Security Analysts? Accounting Review 74, 185-200.

Petersen, Mitchell A., 2007, Estimating Standard Errors in Finance Panel Data Sets: Comparing Approaches, forthcoming in Review of Financial Studies.

Smith, Adam, 1776, An Inquiry into the Nature and Causes of the Wealth of Nations, Fifth Edition (1904), ed. by E. Cannan. London: Methuen and Co., Ltd.

Stigler, George J., 1958, The Economics of Scale, Journal of Law and Economics 1, 54-71.

Teoh, Siew Hong, and T. J. Wong, 2002, Why New Issues and High-Accrual Firms Underperform: The Role of Analysts' Credulity, Review of Financial Studies 15, 869-900.

Tirole, Jean, 1988, The Theory of Industrial Organization. Cambridge, MA: MIT Press.

Winter, Sidney G., 1971, Satisficing, Selection, and the Innovating Remnant, Quarterly Journal of Economics 85, 237-261. 


\section{Table I}

\section{Empirical Relation between G-index and HHI}

This table reports summary statistics on the empirical relation between the G-index and the HHI. G-index is the Governance index of Gompers, Ishii, and Metrick (2003), which is obtained from the IRRC database. Democracy firms are firms with a G-index of 5 or less, while Dictatorship firms are firms with a G-index of 14 or higher. HHI is the Herfindahl-Hirschman index, which is computed as the sum of squared market shares of all firms in an industry. Industries are classified using the 48 industry classification scheme by Fama and French (1997, "FF"). Market shares are computed based on firms' sales (Compustat item \#12) using all firms in the Compustat universe. The sample period is from 1990 to 2006.

Panel (A): Empirical Distribution of the HHI among Democracy and Dictatorship Firms

\begin{tabular}{lccccc}
\hline & $\begin{array}{c}\text { First HHI } \\
\text { Quintile }\end{array}$ & $\begin{array}{c}\text { Second HHI } \\
\text { Quintile }\end{array}$ & $\begin{array}{c}\text { Third HHI } \\
\text { Quintile }\end{array}$ & $\begin{array}{c}\text { Fourth HHI } \\
\text { Quintile }\end{array}$ & $\begin{array}{c}\text { Fifth HHI } \\
\text { Quintile }\end{array}$ \\
\cline { 2 - 6 } Democracy Firms $(\mathrm{G} \leq 5)$ & & & & \\
Mean HHI & 0.02 & 0.04 & 0.05 & 0.07 & 0.15 \\
Median HHI & 0.02 & 0.04 & 0.05 & 0.07 & 0.11 \\
Range of HHI Values & {$[0.01,0.03]$} & {$[0.03,0.04]$} & {$[0.04,0.06]$} & {$[0.06,0.08]$} & {$[0.08,0.58]$} \\
Dictatorship Firms $(\mathrm{G} \geq 14)$ & & & 0.05 & 0.07 & 0.16 \\
Mean HHI & 0.02 & 0.04 & 0.05 & 0.07 & 0.11 \\
Median HHI & 0.02 & 0.04 & {$[0.05,0.06]$} & {$[0.06,0.08]$} & {$[0.08,0.58]$} \\
Range of HHI Values & {$[0.01,0.03]$} & {$[0.03,0.05]$} & & & \\
\hline \hline
\end{tabular}

Panel (B): Empirical Distribution of the G-index across HHI Quintiles

\begin{tabular}{lccccc}
\hline & $\begin{array}{c}\text { First HHI } \\
\text { Quintile }\end{array}$ & $\begin{array}{c}\text { Second HHI } \\
\text { Quintile }\end{array}$ & $\begin{array}{c}\text { Third HHI } \\
\text { Quintile }\end{array}$ & $\begin{array}{c}\text { Fourth HHI } \\
\text { Quintile }\end{array}$ & $\begin{array}{c}\text { Fifth HHI } \\
\text { Quintile }\end{array}$ \\
\cline { 2 - 6 } Mean G-Index & 9.22 & 9.00 & 9.33 & 9.25 & 9.19 \\
Median G-Index & 9.00 & 9.00 & 9.00 & 9.00 & 9.00 \\
Range of G-Index Values & {$[2,17]$} & {$[2,17]$} & {$[2,19]$} & {$[2,18]$} & {$[2,17]$} \\
\hline \hline
\end{tabular}




\section{Table II}

\section{Trading Strategies}

This table reports the results from time-series regressions of monthly excess returns to a hedge portfolio that is long in Democracy firms and short in Dictatorship firms on an intercept ( $\alpha$ or "alpha"), the market factor (RMRF), the size factor (SMB), the book-to-market factor (HML), and the momentum factor (UMD). In Panels (A) and (B) monthly portfolio returns are value-weighted, while in Panel (C) they are equally-weighted. In Panel (A) the hedge portfolios are based on all firms in the sample, while in Panels (B) and (C) they are constructed by dividing both the Democracy and Dictatorship subsamples each into either two or three equal-sized groups by sorting firms according to their HHI. Panel (A) reports both the alpha and factor loadings, while Panels (B) and (C) report only the alpha. Democracy and Dictatorship firms and the HHI are defined in Table I. The RMRF, SMB, and $H M L$ factors are obtained from Kenneth French's webpage. The UMD factor is computed using the procedure described in Carhart (1997). The sample period is from September 1990 to December 1999. $t$-statistics are in parentheses. *,**, and *** denote significance at the $10 \%, 5 \%$, and $1 \%$ level, respectively.

\begin{tabular}{|c|c|c|c|c|c|}
\hline \multicolumn{6}{|c|}{ Panel (A): Value-weighted Democracy-Dictatorship Hedge Portfolios } \\
\hline & $\alpha$ & $R M R F$ & $S M B$ & $H M L$ & $U M D$ \\
\hline GIM (2003) & $\begin{array}{c}0.71 * * * \\
(2.73)\end{array}$ & $\begin{array}{c}-0.04 \\
(0.57)\end{array}$ & $\begin{array}{c}-0.22 * * \\
(2.44)\end{array}$ & $\begin{array}{c}-0.55 * * * \\
(5.50)\end{array}$ & $\begin{array}{l}-0.01 \\
(0.14)\end{array}$ \\
\hline Replication & $\begin{array}{c}0.69 * * * \\
(2.71)\end{array}$ & $\begin{array}{c}-0.04 \\
(0.50)\end{array}$ & $\begin{array}{c}-0.22 * * \\
(2.50)\end{array}$ & $\begin{array}{c}-0.54 * * * \\
(5.21)\end{array}$ & $\begin{array}{l}-0.01 \\
(0.12)\end{array}$ \\
\hline Final Sample & $\begin{array}{c}0.66^{* * * *} \\
(2.57)\end{array}$ & $\begin{array}{c}-0.04 \\
(0.48)\end{array}$ & $\begin{array}{c}-0.22 * * \\
(2.43)\end{array}$ & $\begin{array}{c}-0.54 * * * \\
(5.17)\end{array}$ & $\begin{array}{l}-0.00 \\
(0.05)\end{array}$ \\
\hline
\end{tabular}

Panel (B): Value-weighted Democracy-Dictatorship Hedge Portfolios Sorted by HHI Groups

\begin{tabular}{lccc}
\hline & $\begin{array}{c}\text { Below-median } \\
\text { HHI Group }\end{array}$ & $\begin{array}{c}\text { Above-median } \\
\text { HHI Group }\end{array}$ & \\
\cline { 2 - 3 }$t$-statistic & 0.43 & $\begin{array}{c}1.08^{* * *} \\
(3.13)\end{array}$ & \\
\hline & $(1.47)$ & Medium & Highest \\
& Lowest & HHI Tercile & HHI Tercile \\
\cline { 2 - 4 }$\alpha$ & HHI Tercile & $0.64^{*}$ & $1.47 * * *$ \\
-statistic & 0.30 & $(1.70)$ & $(3.38)$ \\
& $(0.90)$ & & \\
\hline \hline
\end{tabular}

Panel (C): Equally-weighted Democracy-Dictatorship Hedge Portfolios Sorted by HHI Groups

\begin{tabular}{lccc}
\hline & $\begin{array}{c}\text { Below-median } \\
\text { HHI Group }\end{array}$ & $\begin{array}{c}\text { Above-median } \\
\text { HHI Group }\end{array}$ & \\
\cline { 2 - 4 }$t$-statistic & 0.28 & $\begin{array}{c}0.67 * * \\
(2.22)\end{array}$ & \\
\hline & $(0.97)$ & Medium & Highest \\
& Lowest & HHI Tercile & HH Tercile \\
\cline { 2 - 4 }$\alpha$ & HHI Tercile & 0.42 & $0.72^{* *}$ \\
-statistic & 0.28 & $(1.27)$ & $(2.38)$ \\
& $(0.85)$ & & \\
\hline \hline
\end{tabular}


Table III

\section{Trading Strategies: Robustness}

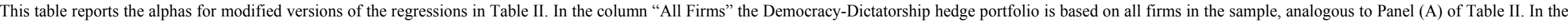

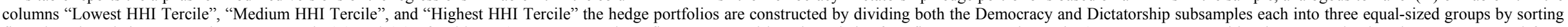

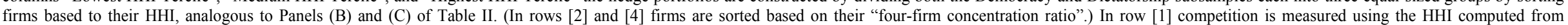

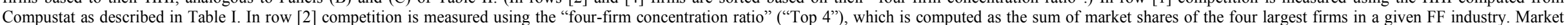

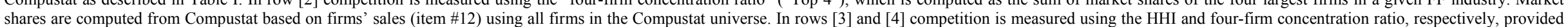

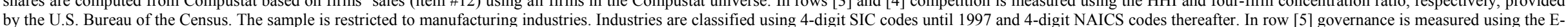

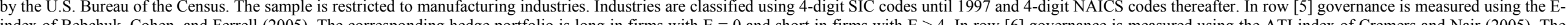

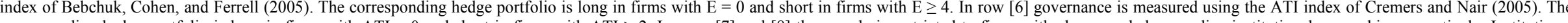

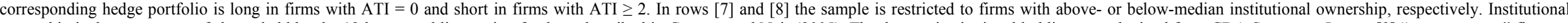

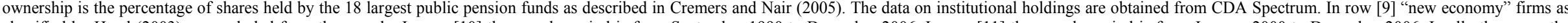

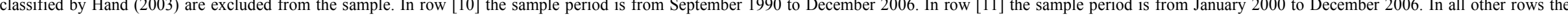
sample period is from September 1990 to December 1999. $t$-statistics are in parentheses. *, ${ }^{* *}$, and ${ }^{* * *}$ denote significance at the $10 \%, 5 \%$, and $1 \%$ level, respectively.

Value-weighted Democracy-Dictatorship Hedge Portfolios

\begin{tabular}{|c|c|c|c|}
\hline $\begin{array}{l}\text { All } \\
\text { Firms }\end{array}$ & $\begin{array}{l}\text { Lowest } \\
\text { HHI Tercile }\end{array}$ & $\begin{array}{c}\text { Medium } \\
\text { HHI Tercile }\end{array}$ & $\begin{array}{c}\text { Highest } \\
\text { HHI Tercile }\end{array}$ \\
\hline $\begin{array}{c}0.66^{* * * *} \\
(2.57)\end{array}$ & $\begin{array}{c}0.30 \\
(0.90)\end{array}$ & $\begin{array}{l}0.64 * \\
(1.70)\end{array}$ & $\begin{array}{c}1.47^{* * *} \\
(3.38)\end{array}$ \\
\hline $\begin{array}{c}0.66^{* * * *} \\
(2.57)\end{array}$ & $\begin{array}{c}0.15 \\
(0.44)\end{array}$ & $\begin{array}{l}0.62 * \\
(1.71)\end{array}$ & $\begin{array}{c}1.35^{* * *} \\
(3.19)\end{array}$ \\
\hline $\begin{array}{l}0.93 * * \\
(2.43)\end{array}$ & $\begin{array}{c}0.02 \\
(0.03)\end{array}$ & $\begin{array}{c}0.69 \\
(1.33)\end{array}$ & $\begin{array}{l}1.50^{* *} \\
(2.46)\end{array}$ \\
\hline $\begin{array}{l}0.91 * * \\
(2.39)\end{array}$ & $\begin{array}{c}0.00 \\
(0.00)\end{array}$ & $\begin{array}{c}0.60 \\
(1.11)\end{array}$ & $\begin{array}{l}1.11^{*} \\
(1.93)\end{array}$ \\
\hline $\begin{array}{c}0.74 * * * \\
(4.09)\end{array}$ & $\begin{array}{c}0.02 \\
(0.09)\end{array}$ & $\begin{array}{c}0.84 * * * \\
(2.92)\end{array}$ & $\begin{array}{c}1.53 * * * \\
(3.42)\end{array}$ \\
\hline $\begin{array}{l}0.29 * \\
(1.91)\end{array}$ & $\begin{array}{c}0.06 \\
(0.25)\end{array}$ & $\begin{array}{c}0.21 \\
(0.98)\end{array}$ & $\begin{array}{c}0.64 * * \\
(2.13)\end{array}$ \\
\hline $\begin{array}{c}0.77 * * * \\
(3.02)\end{array}$ & $\begin{array}{c}0.28 \\
(0.84)\end{array}$ & $\begin{array}{c}0.86^{* *} \\
(2.06)\end{array}$ & $\begin{array}{c}1.60 * * * \\
(3.36)\end{array}$ \\
\hline $\begin{array}{c}0.35 \\
(0.94)\end{array}$ & $\begin{array}{c}0.11 \\
(0.21)\end{array}$ & $\begin{array}{c}0.17 \\
(0.31)\end{array}$ & $\begin{array}{l}0.93^{*} \\
(1.70)\end{array}$ \\
\hline $\begin{array}{l}0.43^{*} \\
(1.71)\end{array}$ & $\begin{array}{c}0.27 \\
(0.79)\end{array}$ & $\begin{array}{c}0.41 \\
(1.05)\end{array}$ & $\begin{array}{c}0.82 * * \\
(2.04)\end{array}$ \\
\hline $\begin{array}{c}0.24 \\
(1.22)\end{array}$ & $\begin{array}{c}0.06 \\
(0.21)\end{array}$ & $\begin{array}{c}0.09 \\
(0.30)\end{array}$ & $\begin{array}{l}0.99 * * \\
(2.55)\end{array}$ \\
\hline $\begin{array}{l}-0.21 \\
(0.65)\end{array}$ & $\begin{array}{l}-0.41 \\
(0.87)\end{array}$ & $\begin{array}{l}-0.19 \\
(0.41)\end{array}$ & $\begin{array}{c}0.26 \\
(0.40)\end{array}$ \\
\hline
\end{tabular}

Equally-weighted Democracy-Dictatorship Hedge Portfolios

\begin{tabular}{|c|c|c|c|}
\hline $\begin{array}{l}\text { All } \\
\text { Firms }\end{array}$ & $\begin{array}{c}\text { Lowest } \\
\text { HHI Tercile }\end{array}$ & $\begin{array}{c}\text { Medium } \\
\text { HHI Tercile }\end{array}$ & $\begin{array}{l}\text { Highest } \\
\text { HHI Tercile }\end{array}$ \\
\hline $\begin{array}{l}0.48 * * \\
(2.19)\end{array}$ & $\begin{array}{c}0.28 \\
(0.85)\end{array}$ & $\begin{array}{c}0.42 \\
(1.27)\end{array}$ & $\begin{array}{l}0.72 * * \\
(2.38)\end{array}$ \\
\hline $\begin{array}{l}0.48^{* *} \\
(2.19)\end{array}$ & $\begin{array}{c}0.32 \\
(0.97)\end{array}$ & $\begin{array}{c}0.55 \\
(1.59)\end{array}$ & $\begin{array}{l}0.56^{* *} \\
(2.08)\end{array}$ \\
\hline $\begin{array}{l}0.51^{*} \\
(1.82)\end{array}$ & $\begin{array}{c}0.31 \\
(0.75)\end{array}$ & $\begin{array}{c}0.44 \\
(1.12)\end{array}$ & $\begin{array}{l}0.81^{*} \\
(1.74)\end{array}$ \\
\hline $\begin{array}{l}0.51^{*} \\
(1.80)\end{array}$ & $\begin{array}{c}0.41 \\
(0.94)\end{array}$ & $\begin{array}{c}0.36 \\
(0.80)\end{array}$ & $\begin{array}{l}0.76^{*} \\
(1.67)\end{array}$ \\
\hline $\begin{array}{c}0.47 * * * \\
(3.01)\end{array}$ & $\begin{array}{c}0.21 \\
(0.89)\end{array}$ & $\begin{array}{l}0.53 * * \\
(2.10)\end{array}$ & $\begin{array}{c}0.68^{* * *} \\
(3.10)\end{array}$ \\
\hline $\begin{array}{l}0.33 * * \\
(2.53)\end{array}$ & $\begin{array}{c}0.13 \\
(0.63)\end{array}$ & $\begin{array}{l}0.42 * * \\
(2.10)\end{array}$ & $\begin{array}{l}0.44 * * \\
(2.19)\end{array}$ \\
\hline $\begin{array}{l}0.49 * \\
(1.84)\end{array}$ & $\begin{array}{c}0.02 \\
(0.04)\end{array}$ & $\begin{array}{c}0.57 \\
(1.41)\end{array}$ & $\begin{array}{l}0.81 * * \\
(2.05)\end{array}$ \\
\hline $\begin{array}{c}0.48 \\
(1.61)\end{array}$ & $\begin{array}{c}0.28 \\
(0.55)\end{array}$ & $\begin{array}{c}0.36 \\
(0.86)\end{array}$ & $\begin{array}{c}0.72 \\
(1.32)\end{array}$ \\
\hline $\begin{array}{l}0.43 * * \\
(2.03)\end{array}$ & $\begin{array}{c}0.24 \\
(0.71)\end{array}$ & $\begin{array}{c}0.35 \\
(1.10)\end{array}$ & $\begin{array}{l}0.72 * * \\
(2.35)\end{array}$ \\
\hline $\begin{array}{l}0.29^{*} \\
(1.77)\end{array}$ & $\begin{array}{c}0.00 \\
(0.00)\end{array}$ & $\begin{array}{c}0.12 \\
(0.48)\end{array}$ & $\begin{array}{c}0.73 * * * \\
(3.12)\end{array}$ \\
\hline $\begin{array}{c}0.20 \\
(0.76)\end{array}$ & $\begin{array}{l}-0.36 \\
(0.91)\end{array}$ & $\begin{array}{c}0.08 \\
(0.19)\end{array}$ & $\begin{array}{l}0.88^{* *} \\
(2.24)\end{array}$ \\
\hline
\end{tabular}


Table IV

\section{Trading Strategies: Industry Effects}

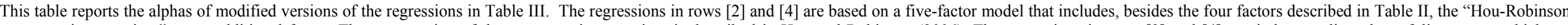

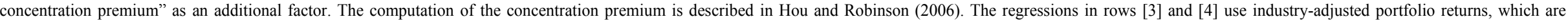

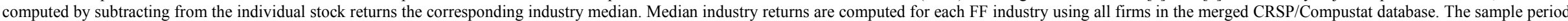
is from September 1990 to December 1999. $t$-statistics are in parentheses. *, **, and $* * *$ denote significance at the $10 \%, 5 \%$, and $1 \%$ level, respectively.

\begin{tabular}{|c|c|c|c|c|c|c|c|c|}
\hline & \multicolumn{4}{|c|}{ Value-weighted Democracy-Dictatorship Hedge Portfolios } & \multicolumn{4}{|c|}{ Equally-weighted Democracy-Dictatorship Hedge Portfolios } \\
\hline & $\begin{array}{l}\text { All } \\
\text { Firms }\end{array}$ & $\begin{array}{c}\text { Lowest } \\
\text { HHI Tercile }\end{array}$ & $\begin{array}{c}\text { Medium } \\
\text { HHI Tercile }\end{array}$ & $\begin{array}{c}\text { Highest } \\
\text { HHI Tercile }\end{array}$ & $\begin{array}{l}\text { All } \\
\text { Firms }\end{array}$ & $\begin{array}{c}\text { Lowest } \\
\text { HHI Tercile }\end{array}$ & $\begin{array}{c}\text { Medium } \\
\text { HHI Tercile }\end{array}$ & $\begin{array}{c}\text { Highest } \\
\text { HHI Tercile }\end{array}$ \\
\hline $\begin{array}{l}\text { [1] 4-Factor Model without } \\
\text { Industry-adjusted Returns }\end{array}$ & $\begin{array}{c}0.66^{* * *} \\
(2.57)\end{array}$ & $\begin{array}{c}0.30 \\
(0.90)\end{array}$ & $\begin{array}{l}0.64 * \\
(1.70)\end{array}$ & $\begin{array}{c}1.47 * * * \\
(3.38)\end{array}$ & $\begin{array}{l}0.48^{* *} \\
(2.19)\end{array}$ & $\begin{array}{c}0.28 \\
(0.85)\end{array}$ & $\begin{array}{c}0.42 \\
(1.27)\end{array}$ & $\begin{array}{l}0.72 * * \\
(2.38)\end{array}$ \\
\hline $\begin{array}{l}\text { [2] 5-Factor Model without } \\
\text { Industry-adjusted Returns }\end{array}$ & $\begin{array}{c}0.66 * * * \\
(2.60)\end{array}$ & $\begin{array}{c}0.30 \\
(0.91)\end{array}$ & $\begin{array}{l}0.64 * \\
(1.69)\end{array}$ & $\begin{array}{c}1.47 * * * \\
(3.45)\end{array}$ & $\begin{array}{l}0.48 * * \\
(2.18)\end{array}$ & $\begin{array}{c}0.28 \\
(0.85)\end{array}$ & $\begin{array}{c}0.42 \\
(1.27)\end{array}$ & $\begin{array}{l}0.72 * * \\
(2.39)\end{array}$ \\
\hline $\begin{array}{l}\text { [3] 4-Factor Model with } \\
\text { Industry-adjusted Returns }\end{array}$ & $\begin{array}{l}0.60 * * \\
(2.10)\end{array}$ & $\begin{array}{c}0.38 \\
(0.92)\end{array}$ & $\begin{array}{c}0.49 \\
(1.38)\end{array}$ & $\begin{array}{l}1.15 * * * \\
(2.72)\end{array}$ & $\begin{array}{l}0.42 * * \\
(2.13)\end{array}$ & $\begin{array}{c}0.31 \\
(1.02)\end{array}$ & $\begin{array}{c}0.28 \\
(0.95)\end{array}$ & $\begin{array}{l}0.67^{* *} \\
(2.29)\end{array}$ \\
\hline $\begin{array}{l}\text { [4] 5-Factor Model with } \\
\text { Industry-adjusted Returns }\end{array}$ & $\begin{array}{l}0.60 * * \\
(2.10)\end{array}$ & $\begin{array}{c}0.39 \\
(0.93)\end{array}$ & $\begin{array}{c}0.49 \\
(1.38)\end{array}$ & $\begin{array}{c}1.15 * * * \\
(2.76)\end{array}$ & $\begin{array}{l}0.42 * * \\
(2.13)\end{array}$ & $\begin{array}{c}0.31 \\
(1.01)\end{array}$ & $\begin{array}{c}0.28 \\
(0.95)\end{array}$ & $\begin{array}{l}0.67^{* *} \\
(2.29)\end{array}$ \\
\hline
\end{tabular}




\section{Table V \\ Fama-MacBeth Return Regressions}

This table reports Fama-MacBeth estimates from monthly cross-sectional regressions of individual stock returns on an intercept, either the G-index or a Democracy dummy, and control variables. All right-hand side variables are lagged. In columns [2] and [4] the G-index and the Democracy dummy are interacted with HHI dummies indicating whether the HHI lies in the lowest ("Low"), middle ("Medium"), or highest ("High") tercile of its empirical distribution. The Democracy dummy equals one if a firm is a Democracy firm. The samples in columns [3] and [4] are restricted to Democracy and Dictatorship firms. The G-index, the HHI, and Democracy firms are defined in Table I. The control variables are firm size, book-to-market ratio, stock price, return from months $t-3$ to $t-2$, from months $t-6$ to $t-4$, and from months $t-12$ to $t-7$, respectively, trading volume of NYSE or AMEX stocks, trading volume of NASDAQ stocks, a NASDAQ dummy, an S\&P 500 dummy, dividend yield, sales growth over the previous five fiscal years, institutional ownership, HHI dummies, and idiosyncratic volatility. A description of all control variables (except for the HHI and idiosyncratic volatility) is found in Gompers, Ishii, and Metrick (2003). Idiosyncratic volatility is the measure $\Psi_{\text {it }}$ described in Ferreira and Laux (2007), lagged by one month. Columns [1] and [3] report the coefficients on the G-index and the Democracy dummy, respectively. Columns [2] and [4] report the coefficients on interaction terms between either the G-index or the Democracy dummy and HHI dummies. The coefficients on the intercept and control variables are not reported. The sample period is from September 1990 to December 1999. $t$-statistics are in parentheses. *, **, and *** denote significance at the $10 \%, 5 \%$, and $1 \%$ level, respectively.

\begin{tabular}{|c|c|c|c|c|}
\hline & {$[1]$} & {$[2]$} & [3] & [4] \\
\hline G-Index & $\begin{array}{l}-0.04 \\
(1.28)\end{array}$ & & & \\
\hline G-Index x HHI (Low) & & $\begin{array}{l}-0.02 \\
(0.21)\end{array}$ & & \\
\hline G-Index x HHI (Medium) & & $\begin{array}{l}-0.02 \\
(0.59)\end{array}$ & & \\
\hline G-Index x HHI (High) & & $\begin{array}{l}-0.12^{*} \\
(1.93)\end{array}$ & & \\
\hline Democracy & & & $\begin{array}{l}0.77 * * \\
(2.43)\end{array}$ & \\
\hline Democracy x HHI (Low) & & & & $\begin{array}{c}0.24 \\
(0.60)\end{array}$ \\
\hline Democracy x HHI (Medium) & & & & $\begin{array}{l}1.00 * \\
(1.72)\end{array}$ \\
\hline Democracy x HHI (High) & & & & $\begin{array}{l}1.77 * * \\
(2.52)\end{array}$ \\
\hline $\begin{array}{l}\text { Number of Months } \\
\text { Number of Observations }\end{array}$ & $\begin{array}{c}112 \\
122,595\end{array}$ & $\begin{array}{c}112 \\
122,595\end{array}$ & $\begin{array}{c}112 \\
21,299\end{array}$ & $\begin{array}{c}112 \\
21,299\end{array}$ \\
\hline
\end{tabular}




\section{Table VI \\ Analysts' Forecast Errors}

This table reports the results from panel regressions of either the mean (or median) $\mathrm{I} / \mathrm{B} / \mathrm{E} / \mathrm{S}$ consensus forecast of annual earnings per share (EPS), the actual I/B/E/S annual EPS, or the forecast error (actual I/B/E/S annual EPS minus mean (or median) I/B/E/S consensus forecast of annual EPS), all scaled down by lagged assets per share, on an intercept, year- and industry-fixed effects, a Democracy dummy, and control variables. In columns [4] to [6] the Democracy dummy is interacted with HHI dummies. Lagged assets per share is the book value of assets (Compustat item \#6) in the previous fiscal year divided by the number of shares in the month of the forecast (from CRSP). All right-hand side variables are lagged. The control variables include HHI dummies, the book-to-market ratio, and firm size. The book-to-market ratio and firm size are each interacted with HHI dummies. The HHI dummies and the Democracy dummy are defined in Table V. Firm size is the logarithm of the book value of assets. The book-to-market ratio is computed as the logarithm of the ratio of the market value of equity (item \#199 $\times$ item \#25) over the book value of equity (item \#60 + item \#74.) All coefficients are multiplied by 100. The sample is restricted to Democracy and Dictatorship firms. Columns [1] to [3] report the coefficients on the Democracy dummy, while columns [4] to [6] report the coefficients on interaction terms between the Democracy dummy and HHI dummies. The coefficients on the intercept and control variables are not reported. Standard errors are clustered at the industry level. The sample period is from 1991 to 1999 . $t$-statistics are in parentheses. *,**, and *** denotes significance at the $10 \%, 5 \%$, and $1 \%$ level, respectively.

Panel (A): Mean Consensus Forecasts of EPS

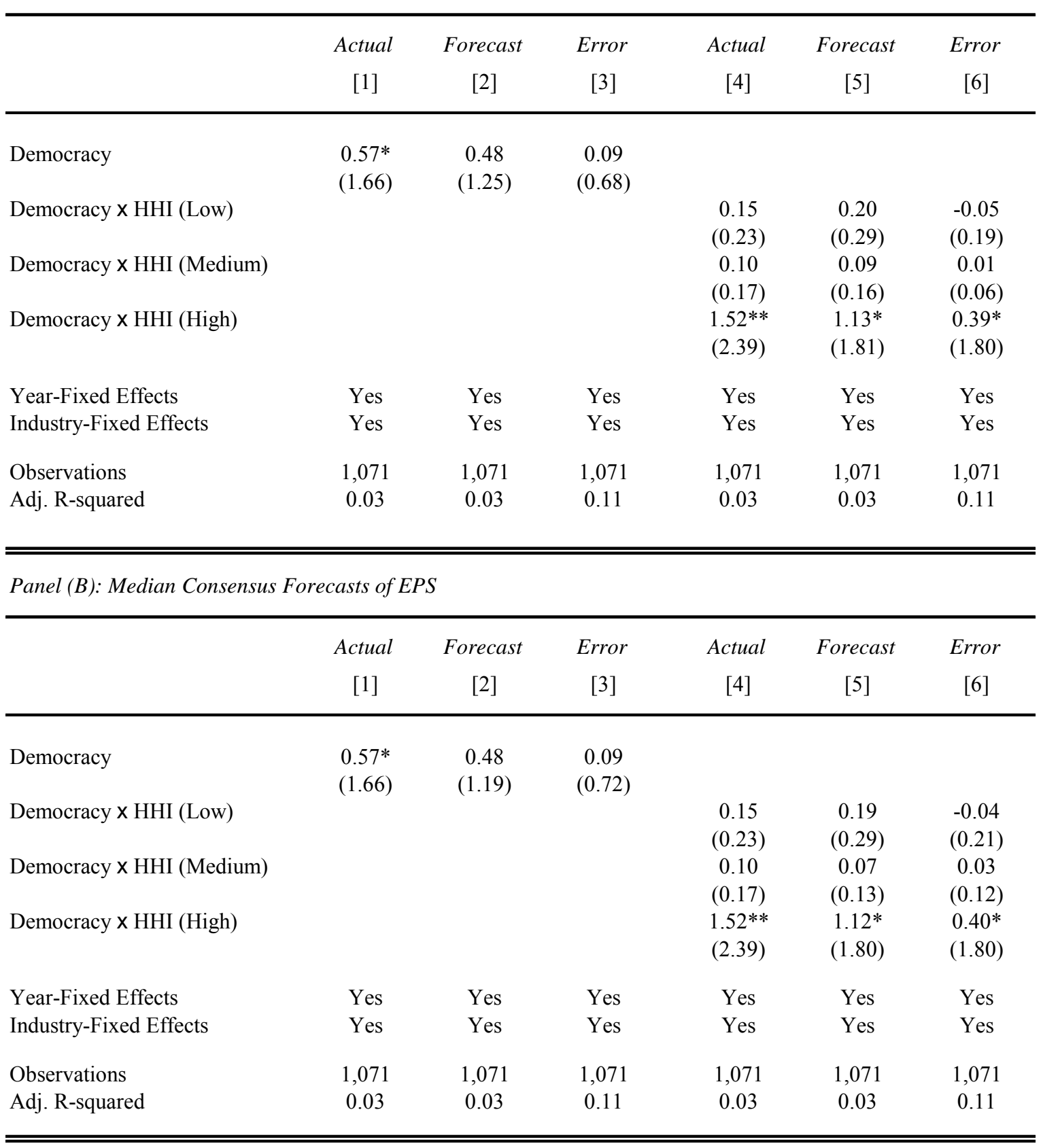




\section{Fama-MacBeth Regressions of Tobin's Q}

This table reports the results from annual cross-sectional regressions of industry-adjusted Tobin's Q on an intercept, the G-index, and control variables. In columns [2] to [4] the intercept, the G-index, and the control variables are interacted with HHI dummies. The last row reports the FamaMacBeth estimates. The G-index and the HHI dummies are defined in Tables I and V, respectively. Tobin's Q is the market value of assets divided by the book value of assets (Compustat item \#6), where the market value of assets is the book value of assets plus the market value of common stock (item \#24 $\times$ item \#25) minus the sum of the book value of common stock (item \#60) and balance sheet deferred taxes (item \#74). Industry-adjusted Tobin's Q is computed by subtracting the industry median in a given FF industry and year. Industry medians are computed using all firms in the Compustat universe. The control variables are firm size, which is the logarithm of the book value of assets, firm age (in logs), an S\&P 500 dummy, and a Delaware dummy. Column [1] reports the coefficient on the G-index, while columns [2] to [4] report the coefficients on interaction terms between the G-index and HHI dummies. The coefficients on the intercept and control variables are not reported. The sample period is from 1990 to 2006. $t$-statistics are in parentheses. $* * *$, and $* * *$ denotes significance at the $10 \%, 5 \%$, and $1 \%$ level, respectively.

\begin{tabular}{|c|c|c|c|c|}
\hline Year & $\begin{array}{c}\text { All Firms } \\
\text { [1] }\end{array}$ & $\begin{array}{c}\text { Lowest } \\
\text { HHI Tercile } \\
\text { [2] }\end{array}$ & $\begin{array}{c}\text { Medium } \\
\text { HHI Tercile } \\
\text { [3] }\end{array}$ & $\begin{array}{c}\text { Highest } \\
\text { HHI Tercile } \\
{[4]}\end{array}$ \\
\hline 1990 & $\begin{array}{c}-0.019 * * \\
(2.26)\end{array}$ & $\begin{array}{l}-0.004 \\
(0.31)\end{array}$ & $\begin{array}{l}-0.024 \\
(1.60)\end{array}$ & $\begin{array}{c}-0.031^{* *} \\
(2.03)\end{array}$ \\
\hline 1991 & $\begin{array}{c}-0.031 * * \\
(2.46)\end{array}$ & $\begin{array}{l}-0.012 \\
(0.59)\end{array}$ & $\begin{array}{l}-0.024 \\
(1.04)\end{array}$ & $\begin{array}{c}-0.061 * * * \\
(2.71)\end{array}$ \\
\hline 1992 & $\begin{array}{c}-0.031 * * * \\
(2.99)\end{array}$ & $\begin{array}{l}-0.013 \\
(0.73)\end{array}$ & $\begin{array}{l}-0.027 \\
(1.44)\end{array}$ & $\begin{array}{c}-0.055^{* * *} * \\
(2.96)\end{array}$ \\
\hline 1993 & $\begin{array}{c}-0.042 * * * \\
(3.65)\end{array}$ & $\begin{array}{l}-0.020 \\
(1.01)\end{array}$ & $\begin{array}{l}-0.030 \\
(1.52)\end{array}$ & $\begin{array}{c}-0.071 * * * \\
(3.46)\end{array}$ \\
\hline 1994 & $\begin{array}{c}-0.034 * * * \\
(3.67)\end{array}$ & $\begin{array}{l}-0.008 \\
(0.53)\end{array}$ & $\begin{array}{c}-0.034^{* *} \\
(2.14)\end{array}$ & $\begin{array}{c}-0.059 * * * \\
(3.56)\end{array}$ \\
\hline 1995 & $\begin{array}{c}-0.035^{* * *} \\
(2.81)\end{array}$ & $\begin{array}{l}-0.020 \\
(0.96)\end{array}$ & $\begin{array}{l}-0.017 \\
(0.79)\end{array}$ & $\begin{array}{c}-0.077 * * * \\
(3.36)\end{array}$ \\
\hline 1996 & $\begin{array}{c}-0.030 * * \\
(2.28)\end{array}$ & $\begin{array}{l}-0.012 \\
(0.54)\end{array}$ & $\begin{array}{l}-0.015 \\
(0.68)\end{array}$ & $\begin{array}{c}-0.068 * * * \\
(2.82)\end{array}$ \\
\hline 1997 & $\begin{array}{l}-0.013 \\
(0.97)\end{array}$ & $\begin{array}{l}-0.006 \\
(0.24)\end{array}$ & $\begin{array}{l}0.006 \\
(0.27)\end{array}$ & $\begin{array}{c}-0.049 * * \\
(2.07)\end{array}$ \\
\hline 1998 & $\begin{array}{c}-0.069 * * * \\
(3.69)\end{array}$ & $\begin{array}{l}-0.028 \\
(0.88)\end{array}$ & $\begin{array}{c}-0.068 * * \\
(1.98)\end{array}$ & $\begin{array}{c}-0.112^{* * *} \\
(3.50)\end{array}$ \\
\hline 1999 & $\begin{array}{c}-0.116^{* * *} \\
(4.41)\end{array}$ & $\begin{array}{l}-0.025 \\
(0.56)\end{array}$ & $\begin{array}{c}-0.163 * * * \\
(3.43)\end{array}$ & $\begin{array}{c}-0.182 * * * \\
(4.01)\end{array}$ \\
\hline 2000 & $\begin{array}{c}-0.091 * * * \\
(3.52)\end{array}$ & $\begin{array}{l}-0.021 \\
(0.49)\end{array}$ & $\begin{array}{c}-0.094^{* *} \\
(2.09)\end{array}$ & $\begin{array}{c}-0.157 * * * \\
(3.44)\end{array}$ \\
\hline 2001 & $\begin{array}{c}-0.033 * * \\
(2.28)\end{array}$ & $\begin{array}{l}0.014 \\
(0.58)\end{array}$ & $\begin{array}{c}-0.067 * * * \\
(2.64)\end{array}$ & $\begin{array}{c}-0.051^{* *} \\
(1.99)\end{array}$ \\
\hline 2002 & $\begin{array}{r}-0.017 \\
(1.60)\end{array}$ & $\begin{array}{l}0.029 \\
(1.61)\end{array}$ & $\begin{array}{c}-0.037^{*} \\
(1.83)\end{array}$ & $\begin{array}{c}-0.054 * * * \\
(2.96)\end{array}$ \\
\hline 2003 & $\begin{array}{c}-0.046^{* * *} \\
(3.26)\end{array}$ & $\begin{array}{l}0.036 \\
(1.56)\end{array}$ & $\begin{array}{c}-0.105^{* * *} \\
(4.18)\end{array}$ & $\begin{array}{c}-0.078 * * * \\
(3.19)\end{array}$ \\
\hline 2004 & $\begin{array}{c}-0.028 * * \\
(2.27)\end{array}$ & $\begin{array}{l}-0.000 \\
(0.02)\end{array}$ & $\begin{array}{l}-0.026 \\
(1.25)\end{array}$ & $\begin{array}{c}-0.058 * * * \\
(2.56)\end{array}$ \\
\hline 2005 & $\begin{array}{c}-0.032 * * \\
(2.53)\end{array}$ & $\begin{array}{l}0.004 \\
(0.17)\end{array}$ & $\begin{array}{c}-0.050^{* *} \\
(2.24)\end{array}$ & $\begin{array}{c}-0.053^{* *} \\
(2.25)\end{array}$ \\
\hline 2006 & $\begin{array}{c}-0.019 \\
(1.52)\end{array}$ & $\begin{array}{l}0.011 \\
(0.50)\end{array}$ & $\begin{array}{r}-0.025 \\
(1.17)\end{array}$ & $\begin{array}{r}-0.031 \\
(1.39)\end{array}$ \\
\hline Fama-MacBeth & $\begin{array}{c}-0.040 * * * \\
(6.10)\end{array}$ & $\begin{array}{l}-0.004 \\
(1.01)\end{array}$ & $\begin{array}{c}-0.047 * * * \\
(4.66)\end{array}$ & $\begin{array}{c}-0.073 * * * \\
(7.36)\end{array}$ \\
\hline
\end{tabular}




\section{Table VIII}

\section{Tobin's Q: Panel Regression with Clustered S.E.}

This table reports the results from panel regressions of industry-adjusted Tobin's Q on an intercept, year- and industry-fixed effects, the G-index, and control variables. In column [2] the intercept, the G-index, and the control variables are interacted with HHI dummies. The G-index and the HHI dummies are defined in Tables I and V, respectively. Industry-adjusted Tobin's Q is defined in Table VII. The control variables are the same as in Table VII. Column [1] reports the coefficient on the G-index, while column [2] reports the coefficients on interaction terms between the G-index and HHI dummies. The coefficients on the intercept and control variables are not reported. The sample period is from 1990 to 2006 . $t$-statistics are in parentheses. $* * *$, and $* * *$ denotes significance at the $10 \%, 5 \%$, and $1 \%$ level, respectively.

\begin{tabular}{lcc}
\hline \hline & {$[1]$} & {$[2]$} \\
& & \\
\hline G-Index & $-0.036^{* * *}$ & \\
& $(3.46)$ & \\
G-Index x HHI (Low) & & -0.003 \\
& & $(0.32)$ \\
G-Index x HHI (Medium) & & $-0.044^{* *}$ \\
& & $(2.03)$ \\
G-Index x HHI (High) & & $-0.067^{* * *}$ \\
& & $(3.37)$ \\
Year-Fixed Effects & Yes & Yes \\
Industry-Fixed Effects & Yes & Yes \\
& & \\
Observations & 20,051 & 20,051 \\
Adj. R-squared & 0.08 & 0.08 \\
& & \\
\hline \hline
\end{tabular}




\section{Table IX \\ Tobin's Q: Robustness}

This table reports the results of modified versions of the regressions in Table VIII. In columns [2] to [4] the intercept, the G-index, and the control variables are interacted with HHI dummies. The G-index and the HHI dummies are defined in Tables I and V, respectively. Industry-adjusted Tobin's $\mathrm{Q}$ is defined in Table VII. The control variables are the same as in Table VII. In row [1] competition is measured using the HHI computed from Compustat as described in Table I. The modifications in rows [2] to [7] are analogous to those in rows [2] to [6] and [9] of Table III. The regression in row [8] uses non-industry-adjusted Tobin's Q. The regression in row [9] uses industry-fixed effects instead of firm-fixed effects. Row [10] is based on median (least absolute deviation) regressions instead of OLS. The $p$-values are computed using block bootstrapping with 200 bootstraps and 48 blocks (one for each FF industry). The bootstrapping procedure is described in Section 4.1. Column [1] reports the coefficient on the G-index, while columns [2] to [4] report the coefficients on interaction terms between the G-index and HHI dummies. The coefficients on the intercept and control variables are not reported. The sample period is from 1990 to 2006. t-statistics (in row [10] p-values) are in parentheses. *,**, and *** denotes significance at the $10 \%, 5 \%$, and $1 \%$ level, respectively.

\begin{tabular}{|c|c|c|c|c|}
\hline & $\begin{array}{c}\text { All Firms } \\
\text { [1] }\end{array}$ & $\begin{array}{c}\text { Lowest } \\
\text { HHI Tercile } \\
\text { [2] }\end{array}$ & $\begin{array}{c}\text { Medium } \\
\text { HHI Tercile } \\
\text { [3] }\end{array}$ & $\begin{array}{c}\text { Highest } \\
\text { HHI Tercile } \\
{[4]}\end{array}$ \\
\hline [1] HHI (Compustat, 48 FF) & $\begin{array}{c}-0.036^{* * *} \\
(3.46)\end{array}$ & $\begin{array}{l}-0.003 \\
(0.32)\end{array}$ & $\begin{array}{c}-0.044^{* *} \\
(2.03)\end{array}$ & $\begin{array}{c}-0.067 * * * \\
(3.37)\end{array}$ \\
\hline [2] Top 4 (Compustat, 48 FF) & $\begin{array}{c}-0.036^{* * *} \\
(3.46)\end{array}$ & $\begin{array}{l}-0.005 \\
(0.43)\end{array}$ & $\begin{array}{c}-0.044^{*} \\
(1.83)\end{array}$ & $\begin{array}{c}-0.061 * * * \\
(3.26)\end{array}$ \\
\hline [3] HHI (Census, Manuf. Ind.) & $\begin{array}{c}-0.047 * * * \\
(3.24)\end{array}$ & $\begin{array}{l}-0.015 \\
(1.06)\end{array}$ & $\begin{array}{c}-0.041 * * \\
(2.12)\end{array}$ & $\begin{array}{c}-0.092 * * \\
(2.14)\end{array}$ \\
\hline [4]Top 4 (Census, Manuf. Ind.) & $\begin{array}{c}-0.047 * * * \\
(3.24)\end{array}$ & $\begin{array}{l}-0.013 \\
(1.03)\end{array}$ & $\begin{array}{c}-0.038 * * \\
(2.19)\end{array}$ & $\begin{array}{c}-0.092 * * * \\
(2.57)\end{array}$ \\
\hline [5] E-Index & $\begin{array}{c}-0.103^{* * *} \\
(4.70)\end{array}$ & $\begin{array}{l}-0.040 \\
(1.23)\end{array}$ & $\begin{array}{c}-0.130 * * * \\
(2.59)\end{array}$ & $\begin{array}{c}-0.148^{* * *} \\
(4.40)\end{array}$ \\
\hline [6] ATI & $\begin{array}{c}-0.089 * * * \\
(3.15)\end{array}$ & $\begin{array}{l}-0.022 \\
(0.47)\end{array}$ & $\begin{array}{c}-0.122 * * \\
(1.99)\end{array}$ & $\begin{array}{c}-0.135^{* * * *} \\
(2.72)\end{array}$ \\
\hline [7] Excluding "New Economy" & $\begin{array}{c}-0.031 * * * \\
(3.42)\end{array}$ & $\begin{array}{l}-0.001 \\
(0.16)\end{array}$ & $\begin{array}{c}-0.041^{* *} \\
(2.07)\end{array}$ & $\begin{array}{c}-0.058 * * * \\
(3.49)\end{array}$ \\
\hline [8] Non-industry-adjusted Tobin's Q & $\begin{array}{c}-0.035^{* * *} \\
(3.40)\end{array}$ & $\begin{array}{l}-0.003 \\
(0.22)\end{array}$ & $\begin{array}{c}-0.044^{*} \\
(1.87)\end{array}$ & $\begin{array}{c}-0.068^{* * * *} \\
(3.43)\end{array}$ \\
\hline [9] Firm-Fixed Effects & $\begin{array}{c}-0.021 * \\
(1.75)\end{array}$ & $\begin{array}{l}0.003 \\
(0.30)\end{array}$ & $\begin{array}{l}-0.018 \\
(0.91)\end{array}$ & $\begin{array}{c}-0.052 * * * \\
(2.91)\end{array}$ \\
\hline [10] Median Regression & $\begin{array}{l}-0.007 * * \\
(\mathrm{p}=0.02)\end{array}$ & $\begin{array}{c}-0.001 \\
(p=0.97)\end{array}$ & $\begin{array}{l}-0.013 * \\
(p=0.07)\end{array}$ & $\begin{array}{c}-0.022 * * * \\
(\mathrm{p}=0.00)\end{array}$ \\
\hline
\end{tabular}


Table X

\section{Operating Performance}

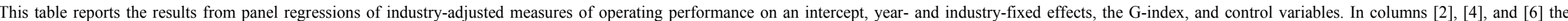

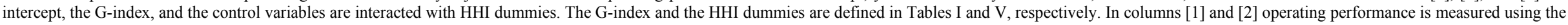

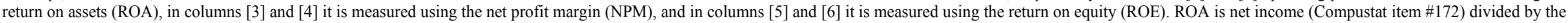

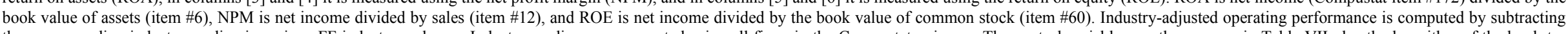

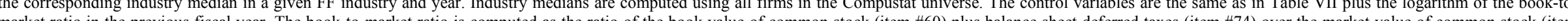

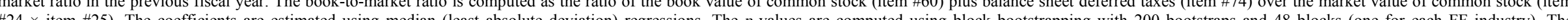

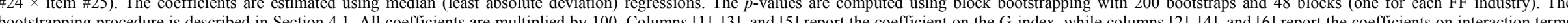

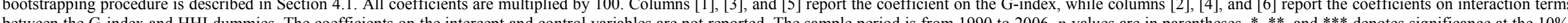
between the G-index and HHI $5 \%$, and $1 \%$ level, respectively.

\begin{tabular}{|c|c|c|c|c|c|c|}
\hline & \multicolumn{2}{|c|}{ ROA } & \multicolumn{2}{|c|}{ NPM } & \multicolumn{2}{|c|}{ ROE } \\
\hline & {$[1]$} & [2] & [3] & [4] & [5] & {$[6]$} \\
\hline G-Index & $\begin{array}{c}-0.071 * * * \\
(\mathrm{p}=0.00)\end{array}$ & & $\begin{array}{c}-0.078 * * * \\
(\mathrm{p}=0.00)\end{array}$ & & $\begin{array}{c}-0.015 \\
(p=0.56)\end{array}$ & \\
\hline G-Index x HHI (Low) & & $\begin{array}{c}-0.006 \\
(p=0.97)\end{array}$ & & $\begin{array}{c}-0.031 \\
(\mathrm{p}=0.61)\end{array}$ & & $\begin{array}{c}0.005 \\
(p=0.68)\end{array}$ \\
\hline G-Index x HHI (Medium) & & $\begin{array}{c}-0.109 * * * \\
(\mathrm{p}=0.00)\end{array}$ & & $\begin{array}{l}-0.094^{*} \\
(p=0.08)\end{array}$ & & $\begin{array}{c}-0.032 \\
(p=0.63)\end{array}$ \\
\hline G-Index x HHI (High) & & $\begin{array}{c}-0.140 * * * \\
(\mathrm{p}=0.00)\end{array}$ & & $\begin{array}{c}-0.117 * * * \\
(\mathrm{p}=0.00)\end{array}$ & & $\begin{array}{l}-0.085^{*} \\
(p=0.08)\end{array}$ \\
\hline Year-Fixed Effects & Yes & Yes & Yes & Yes & Yes & Yes \\
\hline Industry-Fixed Effects & Yes & Yes & Yes & Yes & Yes & Yes \\
\hline Observations & 19,667 & 19,667 & 19,667 & 19,667 & 19,667 & 19,667 \\
\hline Pseudo R-squared & 0.21 & 0.21 & 0.06 & 0.06 & 0.06 & 0.06 \\
\hline
\end{tabular}

